\title{
Light elements in the Earth's core
}

\author{
Kei Hirose ${ }^{1,2 *}$, Bernard Wood ${ }^{3}$ and Lidunka Vočadlo ${ }^{4}$ \\ ${ }^{1}$ Earth-Life Science Institute, Tokyo Institute of Technology, Tokyo, Japan. \\ ${ }^{2}$ Department of Earth and Planetary Science, The University of Tokyo, Tokyo, Japan. \\ ${ }^{3}$ Department of Earth Sciences, University of Oxford, Oxford, UK. \\ ${ }^{4}$ Department of Earth Sciences, University College London, London, UK. \\ *e-mail:kei@elsi.jp
}

\begin{abstract}
Constraining the core's composition is essential for understanding Earth accretion in the early solar system, core formation, and the sustainment of Earth's magnetic field. Earth's outer and inner core exhibit a density deficit relative to pure iron, attributed to the presence of substantial amounts of low atomic number 'light' elements such as sulfur, silicon, oxygen, carbon and hydrogen. However, owing to its inaccessibility, estimates of core composition can only be indirectly obtained by matching results from high-pressure experiments and theoretical calculations with seismic observations. In this Review, we discuss the properties and phase relations of iron alloys under high-pressure and -temperature conditions relevant to the Earth's core. We synthesize mineral physics data with cosmo- and geochemical estimates to give the likely range of compositions for the outer $(\mathrm{Fe}+5 \% \mathrm{Ni}+1.7 \% \mathrm{~S}+0-4.0 \% \mathrm{Si}+0.8-5.3 \% \mathrm{O}+$ $0.2 \% \mathrm{C}+0-0.26 \% \mathrm{H}$ by weight) and inner $(\mathrm{Fe}+5 \% \mathrm{Ni}+0-1.1 \% \mathrm{~S}+0-2.3 \% \mathrm{Si}+0-0.1 \% \mathrm{O}$ $+0-1.3 \% \mathrm{C}+0-0.23 \% \mathrm{H}$ by weight) core. The exact composition of the core remains unknown. However, in the future, tighter constraints on the temperature of the core, as well as better connections between the solid inner core and liquid outer core compositions, will help narrow the range of potential light element compositions.
\end{abstract}

\section{Website summary:}

Although the presence of 'light' elements (such as S, Si, O, C, H) can explain the core's density deficit, the exact composition of the core remains unknown. This Review explores the likely range of outer and inner core compositions and their implications.

\section{Key Messages:}

- Constraining the light element composition of the core has profound implications for understanding Earth's building blocks, accretion history, core formation and evolution processes, as well as present-day core temperature and dynamics.

- The nature and concentrations of light elements have been hotly debated since the 1950s, but advances in mineral physics and cosmo- and geochemical estimates suggest the likely range of liquid outer core composition is: $\mathrm{Fe}+5 \% \mathrm{Ni}+1.7 \% \mathrm{~S}+0-4.0 \% \mathrm{Si}+0.8-5.3 \%$ $\mathrm{O}+0.2 \% \mathrm{C}+0-0.26 \% \mathrm{H}$ by weight.

- Ab initio molecular dynamic simulations have shown that the compositional range of alloys that satisfy the seismic constraints for the solid inner core is: $\mathrm{Fe}+5 \% \mathrm{Ni}+0-1.1 \%$ $\mathrm{S}+0-2.3 \% \mathrm{Si}+0-0.1 \% \mathrm{O}+0-1.3 \% \mathrm{C}+0-0.23 \% \mathrm{H}$ by weight. 
- Crystallisation of oxides and metal near the surface and center of the core, respectively, could drive liquid core convection, thus enabling the generation and maintenance of the Earth's magnetic field.

\section{Introduction}

Earth's core is primarily made of iron, however, since the 1950s it has been discussed that the core is unlikely to be pure $\mathrm{Fe}$ or Fe-Ni alloy — instead, the core probably contains a certain amount of low atomic number "light" elements ${ }^{1,2}$. However, as the core is located $>2,890 \mathrm{~km}$ deep and is thus not directly accessible, it is impossible to precisely obtain the core chemical composition. Nevertheless, constraining the core composition is essential to understand the present state of the core, which depends strongly on the light element abundances. Indeed, core temperatures remain highly uncertain, for example, temperature estimates for the core side of the core-mantle boundary $(\mathrm{CMB})$ range from $3,400 \mathrm{~K}^{3,4}$ to $4,600 \mathrm{~K}^{5,6}$. In contrast, the core (136-364 GPa) pressure range has been precisely obtained by geophysical observations ${ }^{7}$. Furthermore, the core light element composition provides critical insights into Earth accretion and core segregation processes (Fig. 1a).

During the early stages of the solar system, the Earth was formed by the accretion of impactors such as planetesimals (or pebbles) and protoplanets ${ }^{8}$. While impactor silicate merged into a magma ocean that covered the early Earth's surface, impactor metal broke into small droplets and sank to the bottom of the magma ocean where it chemically equilibrated with silicate melts ${ }^{9,10}$, before sinking further down as large metal diapirs through the primitive mantle to form the early core (Fig. 1a). The metal diapirs likely descended rapidly without chemical interaction (element partitioning) with the solid mantle ${ }^{11}$. Siderophile (iron-loving) elements would have preferentially partitioned into metal phases over silicate melts.

Therefore, the plausible major light elements in the core ${ }^{12-14}$ are limited to S, Si, O, C, and $\mathrm{H}$, because they should be abundant in the solar system and can partition into liquid Fe under relevant conditions. The $\mathrm{N}, \mathrm{K}$ and $\mathrm{Mg}$ inventories of the core, which are minor but important to provide insight into Earth's building blocks, heat production and core convection, respectively, have been investigated under Earth's core segregation conditions using metalsilicate partitioning experiments ${ }^{15-19}$. Metal-silicate partitioning data should help constrain the concentrations of each light element in core-forming metals (but uncertainties remain owing to unknowns in the extent of chemical equilibrium ${ }^{20}$ ) and their abundances in the bulk silicate Earth (BSE). Such partitioning data have been reported for all of S, Si, O, C and $\mathrm{H}^{21-27}$.

The Earth's core constitutes $32 \%$ by mass and $16 \%$ in volume of the planet ${ }^{28}$ (Fig. 1b). The outer $96 \mathrm{vol} \%$ of the core is molten, with a solid central inner core making up the remaining $4 \%$. The most straightforward constraint for the present-day outer core composition is a comparison of the density $(\rho)$ and compressonal $(\mathrm{P}-)$ wave velocity $\left(V_{\mathrm{P}}\right)$ of liquid iron alloys $\mathrm{s}^{29,30}$ with seismological observations ${ }^{7,31}$. Both ab initio calculations ${ }^{29,30,32}$ and static compression experiments ${ }^{33-38}$ are used to determine the $\rho$ and $V_{\mathrm{P}}$ of liquid $\mathrm{Fe}$ and $\mathrm{Fe}$-alloys containing the possible major light elements under high-pressure and -temperature $(P-T)$ relevant to Earth's core conditions.

A solid Fe-alloy coexisting with the liquid outer core at the inner core boundary (ICB) should also have $\rho, V_{\mathrm{P}}$ and shear (S-)wave velocity $\left(V_{\mathrm{S}}\right)$ that match observations of the inner core $^{7}$. The $\rho, V_{\mathrm{P}}$ and $V_{\mathrm{S}}$ of solid $\mathrm{Fe}^{32,39,40}$ and Fe-alloys ${ }^{41-44}$ have been examined by theoretical calculations and experiments to core conditions and compared with inner core observations ${ }^{7}$. In addition, melting phase relations in iron alloy systems can also constrain the light element concentration of the outer core, since the solid inner core crystallises from the liquid core. The 
liquid outer core must crystallise solid Fe with small amounts of light elements, instead of light-element-rich compounds such as $\mathrm{FeO}$, to form the dense inner core. Melting experiments performed to core pressures have explored the compositional range of liquids that crystallise $\mathrm{Fe}$ in binary and ternary $\mathrm{Fe}$-alloy ( $\mathrm{Fe}+$ two light elements) systems ${ }^{45-48}$; for example, $\mathrm{O}$ concentration in the outer core must be less than the amount of $\mathrm{O}$ in liquid that crystallises $\mathrm{FeO}$.

In this Review, we combine cosmochemical constraints with results from mineral physics experiments to synthesise multi-disciplinary constraints on inner and outer core compositions in the Fe-Ni-S-Si-O-C-H system. We discuss the implications for Earth accretion, core formation, evolution, and the present state and dynamics of the core and the overlying lowermost mantle. The possible ranges of outer and inner core compositions discussed here could be narrowed down with further knowledge of liquidus temperatures of Fe-alloys, tighter constraints on the partitioning of light elements between solid Fe and liquid Fe-alloys, and a better understanding of the stratified $\mathrm{E}^{\prime}$ layer origin at the top of the core.

\section{Cosmochemical estimates}

Carbonaceous chondrite meteorites, in particular CI chondrites are thought to represent the basic planet-building material in the solar system. The ratios of almost all elements in chondrite meteorites (except the most volatile, $\mathrm{H}, \mathrm{C}, \mathrm{O}, \mathrm{N}$ and the noble gases) mimic the Sun's composition.

The relationship of the BSE to this primitive meteorite composition is more complex owing to both element loss through volatility and element partitioning into core metals (Fig. 2). To demonstrate this complexity, BSE composition can be plotted as a function of the temperature at which $50 \%$ of the element of interest would condense from a gas of solar composition ${ }^{49}$. For clarity, we have concentrated on those elements which are abundant enough to affect the properties of Earth's core markedly. For example, highly refractory and lithophile (silicateloving) elements condense at very high temperatures and are unlikely to be substantially partitioned into the core ( $\mathrm{Ca}, \mathrm{Al}$ and the REE for example) - indeed, these elements are found in the same ratio in BSE and the chondritic reference (Fig. 2). In contrast, some abundant, moderately refractory elements known to dissolve readily in liquid $\mathrm{Fe}$, including Fe itself, are depleted in silicate Earth relative to the CI meteorite reference (Fig. 2). These elements are siderophile and were lost to the core. A cosmochemical estimate of the composition of Earth's core can be made simply by estimating the 'missing' mass relative to the concentration of the element in CI chondrites, with respect to these moderately refractory elements.

Note that the more volatile, low-temperature lithophile condensates such as $\mathrm{In}$ and $\mathrm{Cl}$ are also depleted relative to the chondritic reference in the silicate Earth, leading to the so-called 'volatility trend' (black line, Fig. 2). The trend line is drawn through the abundances in silicate Earth of elements believed to be almost entirely absent from the core, which indicates that the lower the condensation temperature of an element, the greater its depletion in the Earth. Calculating the $\mathrm{S}$ content of Earth's core by comparing its concentration in the silicate Earth with the approximate position of the black trend line leads to about $1.7 \mathrm{wt} \% \mathrm{~S}\left(\mathrm{REFS}^{28,50}\right.$ ) in a core that constitutes $32.3 \%$ of the mass of the Earth.

The core contents of the more abundant moderately refractory elements $\mathrm{Fe}$ and $\mathrm{Ni}$ have been estimated similarly, leading to values of $\sim 85 \mathrm{wt} \% \mathrm{Fe}$ and $5 \mathrm{wt} \% \mathrm{Ni}$ in the core ${ }^{28,49}$. Si is abundant and siderophile under certain conditions and is depleted slightly in silicate Earth relative to CI chondrites. The depletion in Si could plausibly be ascribed either to volatility or dissolution in the core. However, if we take the latter and make the simplest assumption that bulk Earth has the same $\mathrm{Si} / \mathrm{Mg}$ ratio (1.1) as virtually all carbonaceous chondrites (including 
$\mathrm{CI})$, then the core would be expected to contain about $7 \mathrm{wt} \% \mathrm{Si}\left(\mathrm{REF}^{51}\right)$. This $\mathrm{Si}$ estimate is also consistent with determinations of $\mathrm{Si}$ isotopic fractionation between $\mathrm{Fe}$-metal and silicate (the isotope ${ }^{28} \mathrm{Si}$ is partitioned preferentially into metal phases relative to ${ }^{30} \mathrm{Si}$ ). For example, Si concentrations of 6-8 wt $\%$ in the core would help explain the higher ${ }^{30} \mathrm{Si} /{ }^{28} \mathrm{Si}$ isotopic ratio in BSE, relative to chondrites ${ }^{52-54}$. However, when considering the range of chondrite ${ }^{30} \mathrm{Si} /{ }^{28} \mathrm{Si}$ and $\mathrm{Si}$ contents, a wider range of $0-9.6 \mathrm{wt} \% \mathrm{Si}$ in the core is plausible ${ }^{55}$.

$\mathrm{S}$ and Si concentrations at the estimated levels should be sufficient to produce the density deficit of the outer core, which would imply little involvement of the other cosmically abundant elements, $\mathrm{H}, \mathrm{C}$ and $\mathrm{O}$. However, it is important to note that the cosmochemically-estimated $\mathrm{S}$ and $\mathrm{Si}$ contents of the core rely on the volatility 'trend' being quantitative, which is unrealistic given the observed variations in the contents of these elements in different chondrite groups ${ }^{56}$. Instead, the cosmochemical estimates can indicate that $S$ and Si probably constitute some part of the core's 'light' component. Furthermore, the partitioning behaviour of S and Si between the inner core and the outer core ${ }^{46,57}$ suggests that $\mathrm{S}$ and $\mathrm{Si}$ are not the only light elements in the core. Also, compositions involving only $\mathrm{S}$ and $\mathrm{Si}$ as the light elements do not produce the required density jump at the ICB (outer core-inner core boundary).

\section{Density and velocity of $\mathrm{Fe}$ and alloys}

Deviations in physical properties of the core from the properties of pure Fe under core conditions are attributed to the presence of light elements in the core. In this section, we review properties of $\mathrm{Fe}$ and Fe-alloys under core conditions from experiments and theoretical calculations, in comparison to the observed density and velocity of the core obtained through seismic constraints.

\section{Liquid Fe alloys and the outer core}

Seismology has provided reference $\rho$ and $V_{\mathrm{P}}$ profiles for the outer core ${ }^{7,31}$, which are important constraints on the liquid core composition. The $\rho$ and $V_{\mathrm{P}}$ of liquid $\mathrm{Fe}$ and $\mathrm{Fe}$-alloys have been examined for Earth's outer core conditions by $a b$ initio calculations ${ }^{29,30,32}$, providing the effect of each candidate light element on decreasing $\rho$ and increasing $V_{\mathrm{P}}$. In addition, although measurements of liquid metals under static high $P-T$ conditions have been technically challenging, advances in experiments ${ }^{33-38}$ using diamond-anvil cell (DAC) techniques have succeeded in obtaining both $\rho$ and $V_{\mathrm{P}}$ of liquid Fe and Fe-alloys to high pressures, close to core conditions.

Static high-pressure measurements ${ }^{33}$ in a DAC have yielded $\rho$ of pure liquid Fe with $\sim 1 \%$ uncertainty by analysing diffuse scattering signals in X-ray diffraction (XRD) data. These results were obtained to $116 \mathrm{GPa}$, close to the low-pressure end of Earth's outer core conditions. When combined with the $V_{\mathrm{P}}$ of liquid Fe (obtained from inelastic X-ray scattering, IXS, measurements to $45 \mathrm{GPa}$ ) and earlier data from shock-compression ${ }^{58}$ to $278-397 \mathrm{GPa}$, the $P$ $T-\rho-V_{\mathrm{P}}-\gamma$ relationship ${ }^{33}$ (where $\gamma$ is the Grüneisen parameter) was obtained for liquid Fe over the entire core pressure range (Box 1). Such experimentally obtained equation of state of liquid pure $\mathrm{Fe}$, as well as earlier theoretical calculations ${ }^{32}$, shows a relatively uniform 6-8\% density deficit and a 4-5\% P-wave velocity excess of the outer core ${ }^{7,31}$ (relative to pure Fe) when assuming an ICB temperature of 5,400 $\mathrm{K}^{13}$. The depth-wise uniform outer core density deficit suggests that its compressibility is similar to that of pure liquid Fe (Box 1) ${ }^{59}$.

The effects of each candidate light element on the $\rho$ and $V_{\mathrm{P}}$ of liquid $\mathrm{Fe}$ have been estimated $^{29,30}$ by comparing $a b$ initio calculations for pure $\mathrm{Fe}$ with those for $\mathrm{Fe}$-alloys containing S, Si, O, C and $\mathrm{H}$ (Fig. 3). The calculations ${ }^{30}$ have shown that if the outer core 
includes only a single light element, it contains either $13.3-14.4 \% \mathrm{~S}, 9.3-9.8 \% \mathrm{Si}, 8.4-8.9 \%$ $\mathrm{O}$ or $0.96-0.99 \% \mathrm{H}$ by weight (when $T_{\mathrm{ICB}}=5,400 \mathrm{~K}$ and $\left.T_{\mathrm{CMB}}=4,137 \mathrm{~K}\right)^{13}$. Such estimates give the maximum possible concentration for each element except for $\mathrm{C}$. These compositional ranges are approximately consistent with earlier estimates ${ }^{13}$ based on the densities of solid $\mathrm{Fe}$ alloys ${ }^{59,60}$ measured at high- $P$ and room- $T$. The 'best-fits' ${ }^{30}$ when considering only single light element are $\mathrm{H}$ (for $T_{\mathrm{ICB}}=5,400-4,800 \mathrm{~K}$ ) or $\mathrm{O}$ (for $T_{\mathrm{ICB}}=6,000 \mathrm{~K}$ ). The latter conclusion is consistent with the suggestion that $\mathrm{O}$ must be present in the liquid core if the core temperature is relatively high $^{29}$, based on calculations performed at $T_{\mathrm{ICB}}=6,300 \mathrm{~K}\left(T_{\mathrm{CMB}}=4,300 \mathrm{~K}\right)$. At such a high temperature, the maximum concentration of each individual light element was estimated $2.0-2.4 \% \mathrm{~S}, 4.3-4.5 \% \mathrm{Si}, 5.1-5.8 \% \mathrm{O}$ and $3.7-3.9 \% \mathrm{C}$ by weight $^{29}$.

In experiments, the effects of $\mathrm{S}^{35}, \mathrm{Si}^{37}$ and $\mathrm{C}^{38}$ on increasing $V_{\mathrm{P}}$ (for a given concentration of light element) are greater than obtained from $a b$ initio calculations ${ }^{29,30}$, which can lead to lower estimates of the maximum permissible concentrations of these light elements in the outer core. The densities of liquid $\mathrm{Fe}^{33}, \mathrm{Fe}-\mathrm{Ni}-\mathrm{S}^{34}, \mathrm{Fe}-\mathrm{Ni}-\mathrm{Si}^{34}$ and $\mathrm{Fe}-\mathrm{C}^{36}$ have been obtained experimentally in a DAC up to $94 \mathrm{GPa}$. The $V_{\mathrm{P}}$ of liquid $\mathrm{Fe}$ and $\mathrm{Fe}$-alloys have been measured to $20 \mathrm{GPa}$ by an ultrasonic method in a large-volume press ${ }^{61,62}$ and to $70 \mathrm{GPa}$ by IXS measurements in a DAC ${ }^{33,35,37,38}$. The discrepancies between theory and experiments are possibly due to the presence of magnetic moments in iron alloys ${ }^{37}$ at current experimental pressure ranges, which are below those of the core ( $<94 \mathrm{GPa})$. Nevertheless, both experiments and $a b$ initio calculations indicate that a wide range of liquid compositions can fit the seismic properties of the outer core.

\section{Solid Fe alloys and the inner core}

For the inner core, seismology provides a reference on $V_{\mathrm{S}}$ as well as $\rho$ and $V_{\mathrm{P}}$, which impose constraints on light element $\mathrm{S}, \mathrm{Si}, \mathrm{C}$ and $\mathrm{H}$ concentrations. $\mathrm{O}$ is believed to be practically absent in the inner core because it is not soluble in solid $\mathrm{Fe}^{63}$ and does not partition into the solid ${ }^{46,57}$. Both experiments ${ }^{64,65}$ and theory ${ }^{43,44}$ indicate that $\mathrm{C}$ and $\mathrm{H}$ are key impurity elements that explain the high $V_{\mathrm{P}} / V_{\mathrm{S}}$ ratio observed in the inner core compared to pure Fe.

The $\rho$ and $V_{\mathrm{P}}$ of solid Fe and Fe-alloys have been extensively measured at high pressures, but mainly at room temperature. Results are extrapolated to inner core conditions by using a linear relationship between $\rho$ and $V_{\mathrm{P}}$ (Birch's law), in which temperature is not explicitly involved. However, recent measurements ${ }^{66}$ performed at high $P-T$ reported a strong temperature effect on the $\rho-V_{\mathrm{P}}$ relation.

The density increase across the ICB is $0.82 \pm 0.18 \mathrm{~g} / \mathrm{cm}^{3}\left(\mathrm{REFS}^{7,67}\right)$, giving an inner core density with an uncertainty of $1-2 \%$. As with the outer core, the solid inner core also appears to be less dense by $4-5 \%$ than pure Fe under the same conditions ${ }^{32,39,40}$ (Box 1), indicating the inclusion of minor amounts of one or more light elements in solid $\mathrm{Fe}$ or $\mathrm{Fe}-\mathrm{Ni}$ alloy. For the inner core, the stable phase of pure iron is generally considered to have the hcp structure $32,43,68,69$ and as with the outer core, there have been numerous attempts to obtain the inner core composition by matching possible compositions in hcp Fe with seismic observables.

$\mathrm{Fe}-\mathrm{H}^{66}$ and $\mathrm{Fe}-\mathrm{Si}$ alloys ${ }^{41,42}$ appear to be able to match the $\rho$ and $V_{\mathrm{P}}$ of the inner core. However, one of the characteristic features of the inner core is its high $V_{\mathrm{P}} / V_{\mathrm{S}}$ ratio (low $V_{\mathrm{S}}$ ) compared to the extrapolated properties of pure solid Fe. It could be due to the effect of anelasticity $^{70}$ (viscoelastic relaxation in iron) at inner core temperatures close to its melting temperature. It has been also suggested that the high $V_{\mathrm{P}} / V_{\mathrm{S}}$ ratio is reconciled with $\mathrm{Fe}_{7} \mathrm{C}_{3}{ }^{64,65}$, but the density of $\mathrm{Fe}_{7} \mathrm{C}_{3}$ is too low to explain the inner core observations ${ }^{71}$. Ab initio calculations carried out at inner core $P-T$ conditions ${ }^{43}$ indicate that none of $\mathrm{S}, \mathrm{Si}$ or $\mathrm{C}$ alone can match all three constraints ( $\mathrm{O}$ cannot be an inner core light elememt as mentioned above). 
However, a wide range of ternary and quaternary compositions within the Fe-S-Si-C system can simultaneously satisfy the density and velocity constraints (Fig. 4). Ternary Fe-Si-H compositions also provide a match with seismology for the inner core ${ }^{44}$.

As with the outer core, obtaining the inner core composition cannot rely just on matching experimental or theoretical results to PREM. Other constraints, in particular the partitioning of the candidate light elements between the outer and inner cores must be considered such that the outer and inner core compositions are constrained simultaneously ${ }^{47}$.

\section{Crystallisation of the dense inner core}

Inner core crystallisation at the ICB places important constraints on the liquid core composition. The density jump observed across the ICB is larger than the density difference between liquid and solid states of $\mathrm{Fe}^{32,33,39,40,57}$ (Box. 1), indicating a depletion in light elements in the solid inner core relative to the outer core. Therefore, the inner core consists of solid Fe (albeit not pure Fe but an alloy containing a small amount of light element(s) and Ni) rather than a lightelement-rich phase such as $\mathrm{Fe}_{2} \mathrm{~S}^{72}, \mathrm{FeSi}, \mathrm{FeO}, \mathrm{Fe}_{7} \mathrm{C}_{3}{ }^{73}$ or $\mathrm{FeH}^{74}$. The outer core composition is considered to be in the liquidus field of $\mathrm{Fe}$ (compositional range of liquids that first crystallise $\mathrm{Fe}$ ), such that it crystallises solid Fe at inner core pressures. In other words, the liquid core composition should be on the Fe-rich side of a multi-element eutectic point, rather than on the light-element-rich side.

High-pressure melting experiments on binary $\mathrm{Fe}$ alloys found that the eutectic liquids contain $\sim 5 \% \mathrm{~S}^{75}, \sim 8 \% \mathrm{Si}^{47}, \sim 15 \% \mathrm{O}^{76}$ and $\sim 3 \% \mathrm{C}^{73}$ by weight at $330 \mathrm{GPa}$ in the Fe-S, Fe-Si, $\mathrm{Fe}-\mathrm{O}$ and $\mathrm{Fe}-\mathrm{C}$ systems, respectively. The effect of $\mathrm{Ni}$ on melting phase relations could be minor ${ }^{77}$ although it is significant at some conditions in the low-pressure range around $20 \mathrm{GPa}^{78}$. These eutectic liquid compositions indicate the maximum concentration of each light element in the outer core ${ }^{45,46}$. The melting phase relations in $\mathrm{Fe}-\mathrm{H}$ have been determined only to 20 $\mathrm{GPa}^{79}$, where the eutectic point is located at $\mathrm{FeH}_{\mathrm{x}}(\mathrm{x}>1)$. The formation of the intermediate compound $\mathrm{FeH}_{2}$ above $67 \mathrm{GPa}^{80}$ suggests that the eutectic point is located between $\mathrm{FeH}$ and $\mathrm{FeH}_{2}$, possibly in the middle $(2.6 \mathrm{wt} \% \mathrm{H})$.

Experiments on the ternary Fe-alloy systems, Fe-S-Si ${ }^{45}$ and $\mathrm{Fe}-\mathrm{S}-\mathrm{O}^{46}$, have demonstrated that the liquidus fields of Fe (Fig. 5a, coloured area) in these ternary systems closely approximate what would be expected from linear interpolation between the eutectics in the binary systems. If this observation can be extended to the Fe-S-Si-O-C-H system, the liquidus field of Fe could be estimated from the weighted composition of all the relevant eutectic compositions. However, due to increased number of components and hence increased entropy of mixing of the liquid relative to the binary eutectic liquids, it is likely that the actual eutectic temperature is lower than any of the binary eutectic temperatures and possible that the eutectic composition is displaced towards the Fe corner.

Some combinations of light elements, such as $\mathrm{Si}+\mathrm{O}^{23,81}, \mathrm{Si}+\mathrm{C}^{82}$ and $\mathrm{C}+\mathrm{H}^{83}$, have simultaneous solubility limits in liquid $\mathrm{Fe}$, constraining maximum concentation of a light element in the outer core when coexisting with others. In particular, the $\mathrm{Si}+\mathrm{O}$ solubility curve at outermost-core conditions could be an important constraint on $\mathrm{Si}$ and $\mathrm{O}$ concentrations in the outer core ${ }^{23,84,85}$ (Fig. 5c). The early core composition might have been enriched in both Si and $\mathrm{O}$ beyond their simultaneous solubility limits in liquid $\mathrm{Fe}$ (under the present-day outermost core conditions). The steel-making literature provides the simultaneous solubility limit ${ }^{81}$ of $\mathrm{Si}+\mathrm{O}$ at ambient pressure, beyond which $\mathrm{Si}+\mathrm{O}$ form $\mathrm{SiO}_{2}$ crystals (Fig. 5b). Such $\mathrm{Si}+\mathrm{O}$ solubility limits have been determined under core pressures ${ }^{23,84,85}$ (Fig. 5c), although 
contradicting experimental results argued for immiscibility between Si-rich and O-rich liquids $^{86}$.

\section{Metal-silicate partitioning}

Metal-silicate partitioning experiments ${ }^{15-19,21,22,24,27}$ and calculations ${ }^{25,26}$ investigate the siderophile or lithophile behaviour of particular elements under conditions for core-forming metal segregation from silicate that occurred during Earth accretion $(>4.5 \mathrm{Ga})$. These results help constrain the concentrations of each light element in the core from their abundances in the BSE. However, large uncertainties remain in element concentrations derived from these methods owing to unknowns both in the BSE concentrations and the extent of chemical equilibrium during core segregation ${ }^{20}$.

\section{Element partitioning during core formation}

$\mathrm{Fe}$ and $\mathrm{Ni}$ are strongly depleted in the BSE relative to $\mathrm{Eu}$ (an element of similar volatility ${ }^{49}$ ) and more refractory elements such as $\mathrm{Ca}$ and $\mathrm{Al}$ (Fig. 2). The depletion of $\mathrm{Fe}$ and $\mathrm{Ni}$ in $\mathrm{BSE}$ is because $\mathrm{Fe}$ and $\mathrm{Ni}$ form a major fraction of the Earth's core, which by mass-balance should contain $\sim 85 \mathrm{wt} \% \mathrm{Fe}$ and $5 \mathrm{wt} \% \mathrm{Ni}$. However, since the 1960s $\left(\mathrm{REF}^{87}\right)$, it has been known that the $\mathrm{Ni}$ content of the mantle $\left(0.186 \mathrm{wt} \%, \mathrm{REF}^{88}\right)$ is too high to be explained by low-pressure equilibration between an Fe-rich core containing $5 \% \mathrm{Ni}$ and a peridotitic silicate melt.

As experimentation moved to higher pressures, the metal-silicate $\left(D^{\text {metal/silicate }}\right)$ partitioning of $\mathrm{Ni}$ was discovered ${ }^{9,10}$ to decrease dramatically with increasing pressure, such that the mantle and core would be in equilibrium with their current contents of $\mathrm{Ni}$ and $\mathrm{Fe}$ (at an extrapolated pressure of about $35 \mathrm{GPa}$ ). The discovery of this partitioning behaviour ${ }^{9,10}$ led to the model of core segregation at the base of a deep $(\sim 1,200 \mathrm{~km})$ magma ocean (Fig. 1a). Furthermore, consideration of moderately refractory elements (for example, $\mathrm{V}, \mathrm{Cr}, \mathrm{Mn}, \mathrm{W}, \mathrm{Mo}, \mathrm{Co}, \mathrm{Nb}$ and $\mathrm{Si})^{89,90}$ led to more realistic multi-stage core formation models incorporating continuous core segregation as the Earth accreted ${ }^{89-92}$.

The suggestion that Earth started accreting as a small, highly reduced body and became more oxidised as it grew was required by matching the concentrations of weakly-siderophile elements $(\mathrm{V}, \mathrm{Cr}$ and $\mathrm{Nb})$ in the silicate Earth to their measured metal-silicate partitioning data. Progressive oxidation during growth is also derived from models which combine an N-body accretion scenario with core-mantle partitioning data ${ }^{92}$. The accretion path from reduced to oxidised yields $\sim 4 \mathrm{wt} \% \mathrm{Si}$ in the core ${ }^{93}$, with some $\mathrm{V}, \mathrm{Cr}, \mathrm{Nb}$ and more siderophile $\mathrm{W}, \mathrm{Mo}, \mathrm{Ni}$ and $\mathrm{Co}$, deposited during the early reduced stages.

In the continuous accretion model, $\mathrm{Si}$ was partitioned into the early core when Earth was a small, reduced low-pressure body and in the more oxidised later stages at high temperatures and pressures ${ }^{92,93}$. Si and $\mathrm{O}$ are added together in the later high-temperature, high-pressure stages $^{90,92}$. While such a continuous accretion model is not a unique solution, substantial amounts of $\mathrm{Si}$ and $\mathrm{O}$ might enter metal phases simultaneously at very high temperatures (especially for metal-silicate partitioning at $>\sim 3,000 \mathrm{~K}$ ), which means that virtually all models ${ }^{22,92,94}$ propose high concentrations of Si and O in core-forming metals (Fig. 5c).

The proposed Si-rich initial core compositions ${ }^{22,92}$ include $\mathrm{Si}+\mathrm{O}$ that on their own are more than (or close to) that required to account for the outer core density deficit and velocity excess $^{29,30}$. In contrast, the O-rich compositions ${ }^{94}$ have $\mathrm{O}$ contents close to the maximum possible (3.8-5.3 wt \%) ${ }^{32,33}$ to be consistent with the observed density jump across the ICB. In neither case, S, C and $\mathrm{H}$ could be accommodated at the levels expected from metal-silicate (core-mantle) partitioning. High concentrations of $\mathrm{Si}$ and $\mathrm{O}$ in core-forming metals could 
possibly be explained by evolution of core composition with time. The core $\mathrm{Si}+\mathrm{O}$ abundances estimated from metal-silicate partitioning during core formation ${ }^{22,92,94}$ are greater than the solubility limit ${ }^{23,84,85}$ in the present-day liquid outer core as far as $T_{\mathrm{CMB}}$ is lower than $\sim 4,300 \mathrm{~K}$ (which is likely) (Fig. 5c). This supersaturation in $\mathrm{Si}+\mathrm{O}$ should, if correct, cause $\mathrm{SiO}_{2}$ crystallisation in the core ${ }^{23,84,85}$.

In addition to $\mathrm{Si}$ and $\mathrm{O}$, metal-silicate partitioning of $\mathrm{S}, \mathrm{C}$ and $\mathrm{H}$ have been examined under high $P-T$ conditions of core formation by experiments and theory. $\mathrm{S}$ is known to be strongly siderophile below $2,500 \mathrm{~K}\left(D^{\text {metal/silicate }}=\sim 100\right)$, although DAC experiments ${ }^{21}$ demonstrated that $\mathrm{S}$ becomes less siderophile with increasing temperature to $>3,500 \mathrm{~K}\left(D^{\text {metal/silicate }}=\sim 10\right)$. This strongly siderophile behaviour at relatively low temperatures suggests that $\mathrm{S}$ was delivered to the Earth only in the later stages of accretion ${ }^{21}$, otherwise mantle concentrations should be larger than observed. Late addition of the Earth's S, cosmochemically estimated to amount to $1.7 \mathrm{wt} \%$ in the core ${ }^{50}$, is also consistent with the $\mathrm{W}$ and Mo contents of silicate Earth $^{90}$ which are sensitive to the $\mathrm{S}$ contents of accreting metal.

$\mathrm{C}$ is known to be highly siderophile under low-pressure conditions. The high cosmochemical abundance of $\mathrm{C}$, coupled with its low BSE abundance $(0.01 \%)^{88}$, led to the suggestion ${ }^{95}$ that $\mathrm{C}$ dissolved extensively into the core and that its concentration in the core is of the order of 2-4 wt $\%$. Some experiments ${ }^{24}$ have, however, shown that carbon becomes less siderophile at high $P-T(37-59 \mathrm{GPa}, 4,200-5,200 \mathrm{~K})$, and a simple continuous accretion model suggests that the maximum core $\mathrm{C}$ content is approximately $0.2 \mathrm{wt} \%$ only.

The metal-silicate partitioning of $\mathrm{H}$ has been controversial in experimental studies ${ }^{27,96-98}$, but the low $D^{\text {metal/silicate }}\left(\right.$ REFS $^{97,98}$ ) is likely to be attributed to hydrogen escape from metal when the sample transformed into bcc Fe during decompression ${ }^{83}$. Other experiments ${ }^{27}$ have demonstrated that hydrogen is strongly siderophile under conditions of core-forming metal segregations, consistent with theoretical calculations ${ }^{25,26}$, and that $0.3-0.6 \mathrm{wt} \% \mathrm{H}$ should have been incorporated into the core. Such an amount is consistent with the maximum determined by $a b$ initio calculations for the solid inner core $(0.03-0.23 \mathrm{wt} \% \mathrm{H})^{44}$, where enhanced superionic mobility of $\mathrm{H}$ reduces the shear velocity towards observed seismological values.

However, estimates of core light element concentrations derived from metal-silicate partitioning data depend strongly on their mantle abundances and core formation scenarios, which both still include large uncertainties.

\section{Isotope fractionation}

Elements partitioning into the core during core segregation left an isotopic signature in the mantle because of changes in oxidation state and differences in bonding. For low atomic number elements this isotope signature should be measurable, although other factors can obscure the signal, such as volatile loss.

The silicate Earth has a higher ${ }^{30} \mathrm{Si} /{ }^{28} \mathrm{Si}$ than chondritic meteorites, consistent with 5-8 wt $\%$ $\mathrm{Si}$ in the core and $21.2 \mathrm{wt} \% \mathrm{Si}$ in the mantle ${ }^{52-54}$ according to isotope fractionation factors derived by theory and experiment. Furthermore, 5-8 wt\% Si in the core is consistent with the cosmo- and geochemical estimates ${ }^{28,49}$ (Fig. 2) and with the continuous accretion models in which Earth became more oxidised as it accreted ${ }^{89,92}$. These lines of evidence point towards a core concentration of $\sim 5 \mathrm{wt} \% \mathrm{Si}$, although $\mathrm{Si}$ concentration could have decreased owing to $\mathrm{SiO}_{2}$ crystallization ${ }^{23,84,85}$ upon secular cooling.

The isotopic systems of $\mathrm{C}$ and $\mathrm{S}$ are difficult to exploit because of the volatilities of the two elements on small asteroidal bodies and in the solar nebula, before accretion to the Earth. However, $\mathrm{C}$ isotope fractionation between liquid iron carbide and graphite (and/or diamond) 
would be consistent with a ${ }^{12} \mathrm{C}$-enriched core ${ }^{99}$. The Earth's mantle exhibits a lower ${ }^{34} \mathrm{~S} /{ }^{32} \mathrm{~S}$ ratio than chondrites, which could also be attributed to isotope fractionation of $\mathrm{S}$ during core segregation $^{100}$.

\section{Possible core composition}

The core cannot be sampled and its exact composition is hard to determine, but here we propose a range of possibilities for the abundance of major light elements based on estimates constrained by the mineral physics and cosmo- and geochemical studies we have discussed. Note that the liquid outer core constitutes $95 \%$ of the entire core's mass.

First, we assume $5 \mathrm{wt} \% \mathrm{Ni}, 1.7 \mathrm{wt} \% \mathrm{~S}$ and $0.2 \mathrm{wt} \% \mathrm{C}$ in the outer core ${ }^{24,28,50} . \mathrm{S}$ is a moderately volatile element unlike $\mathrm{C}$ and $\mathrm{H}$ (which are highly volatile, Fig. 2), so cosmo- and geochemical estimates of its concentration in the core have been consistent with each other ${ }^{28,50,101}$. Properties of $\mathrm{Fe}-\mathrm{C}$ alloys found in mineral physics studies suggest that $\mathrm{C}$ cannot be a major light element in the core ${ }^{29,30,38,59}$. A value of $\sim 0.2 \mathrm{wt} \% \mathrm{C}$ in the liquid core is supported by metal-silicate partitioning experiments under core formation conditions ${ }^{24}$ and mass-balance considerations from the bulk Earth and mantle abundances ${ }^{28}$.

Second, the $\rho$ and $V_{\mathrm{P}}$ of the outer core Fe-alloy must be consistent with seismological observations (Fig. 3). The outer core might be a base metal alloy (Fe, $5 \% \mathrm{Ni}, 1.7 \% \mathrm{~S}, 0.2 \% \mathrm{C}$ ) additionally containing $\mathrm{Si}, \mathrm{O}$ and $\mathrm{H}$. In this case, the maximum amounts of these individual light elements are $7.7-8.3 \%$ for $\mathrm{Si}, 7.0-7.6 \%$ for $\mathrm{O}$ and $0.81-0.85 \%$ for $\mathrm{H}$ by weight, when $T_{\mathrm{ICB}}=5,400 \mathrm{~K}\left(T_{\mathrm{CMB}}=4,137 \mathrm{~K}\right)$ according to ab initio calculations ${ }^{30}$. If earlier calculations ${ }^{29}$ at $T_{\mathrm{ICB}}=6,300 \mathrm{~K}\left(T_{\mathrm{CMB}}=4,300 \mathrm{~K}\right)$ are employed, the liquid core could include $0-3.4 \% \mathrm{Si}$ and $0.8-4.2 \% \mathrm{O}$ in addition to $5 \% \mathrm{Ni}, 2.0 \% \mathrm{~S}$ and $0.2 \% \mathrm{C}$ by weight.

Third, the outer core liquid must crystallise light-element-depleted $\mathrm{Fe}$ at the inner core (Fig. 5a). As discussed above, the liquidus field of $\mathrm{Fe}$ in the Fe-S-Si-O-C-H system can be approximated by a compositional range for mixtures of liquids that are on the Fe-rich side of the eutectic in each binary Fe-alloy system ${ }^{45,46}$. The density jump across the ICB limits O concentration in the outer core to be less than $3.8 \mathrm{wt} \%$ (REF. ${ }^{33}$ ) or $5.3 \mathrm{wt} \%$ (REF. ${ }^{32}$ ) (Box 1). In addition, the present-day liquid core might be saturated in $\mathrm{Si}+\mathrm{O}$, and their concentrations are given by the simultaneous solubility curve in liquid Fe (Fig. 5c) ${ }^{84}$.

Overall these constraints give the possible range of the liquid core composition to be $\mathrm{Fe}+$ $5 \% \mathrm{Ni}+1.7 \% \mathrm{~S}+0-4.0 \% \mathrm{Si}+0.8-5.3 \% \mathrm{O}+0.2 \% \mathrm{C}+0-0.26 \% \mathrm{H}$ by weight (when $T_{\mathrm{ICB}}=$ $5,400-6,300 \mathrm{~K}$ and $T_{\mathrm{CMB}}=4,137-4,300 \mathrm{~K}$ ). Less than $0.26 \mathrm{wt} \% \mathrm{H}$ is marginally consistent with hydrogen's high metal/silicate partition coefficient ${ }^{25,27}$.

The range of possible inner core compositions that account for the observed $\rho, V_{\mathrm{P}}$ and $V_{\mathrm{S}}$ have been estimated as $\mathrm{Fe}+5 \% \mathrm{Ni}+0-1.1 \% \mathrm{~S}+0-2.3 \% \mathrm{Si}+0-0.1 \% \mathrm{O}+0-1.3 \% \mathrm{C}+0$ $0.23 \% \mathrm{H}$ by weight (see Fig. 4 for the range in the Fe-S-Si-C system). Si has often been suggested to be a primary light element in the inner core ${ }^{41,42}$, however, this is likely not true because Si does not explain the high $V_{\mathrm{P}} / V_{\mathrm{S}}$ ratio $^{43,44}$. Here these plausible outer and inner core light element compositions are estimated separately based on respective seismological constraints but are indeed connected through equilibrium element partitioning between solidFe and liquid-Fe-alloy at inner core conditions (Box 1).

\section{Implications}

The melting temperatures, viscosities, element partitioning, and thermal conductivities of iron alloys depend strongly on their light element compositions. Although the possible core 
compositional range still needs to be better constrained, understanding these properties has profound implications for the state, dynamics, formation and evolution of the Earth's core (Fig. $6)$.

\section{[H2] States of the core and lowermost mantle}

An assumed model for the outer core's composition constrains its temperature (Fig. 6). $T_{\text {ICB }}$ corresponds to the liquidus temperature (temperature for the onset of crystallisation) of an outer core liquid at $330 \mathrm{GPa}$, which mineral physics studies can obtain once the liquid core composition is known. Indeed, the liquidus temperature of an Fe-alloy depends largely on its light element composition because the effect on melting temperature reduction is variable among the different candidate light elements. If the core were to contain a single light element, the liquidus temperature of an Fe-H outer core at the ICB could be $\sim 1,000 \mathrm{~K}$ lower than that of an $\mathrm{Fe}-\mathrm{Si}$ core $^{6,83,102}$. A wide range of previous $T_{\mathrm{ICB}}$ estimates (from 4,800 $\mathrm{K}^{3,4,30}$ to 6,300 $\mathrm{K}^{6,29,103}$ ) includes large uncertainties derived from unknown light element composition.

The outer core is believed to be vigorously convecting, and therefore it should exhibit an isentropic temperature profile. Accordingly, the $T_{\text {ICB }}$ gives the entire outer core temperature range ${ }^{13}$ including $T_{\mathrm{CMB}}$ from the observed density profile ${ }^{7,31}$ and the $\gamma$ value. With $\gamma=1.5$ throughout the outer core ${ }^{32}, T_{\mathrm{CMB}}=3,500-4,600 \mathrm{~K}$ is obtained from the range of estimates for $T_{\mathrm{ICB}}=4,800-6,300 \mathrm{~K}$. The $T_{\mathrm{CMB}}$ is key to better understanding the lowermost mantle ${ }^{104,105}$ (Fig. 6), as it gives a temperature increase across the thermal boundary layer at the bottom of the mantle $e^{5}$. The thermal boundary layer is important for understanding the nature of mantle plume upwellings from the $\mathrm{CMB}^{106}$. The nature of the ultralow velocity zones (ULVZs) observed locally above the CMB also remains uncertain; they likely represent partial melts ${ }^{107}$ but could be Fe-rich solids ${ }^{108}$. Partial melting in the lowermost mantle is dependent primarily on the $T_{\mathrm{CMB}}$. $\mathrm{MgSiO}_{3}$-rich post-perovskite should be globally present ${ }^{3,105,109}$ above the CMB unless $T_{\mathrm{CMB}}$ is high enough to stabilise bridgmanite. Narrowing the range of $T_{\mathrm{CMB}}$ would help constrain the temperature gradient above the CMB and thus heat flux from core to mantle, with implications for the style of mantle convection and for core and mantle thermal evolution.

Seismology has revealed complex structures of the inner core such as depth-dependent and hemispherical asymmetric seismic anisotropy ${ }^{110}$. A number of flow deformation mechanisms have been proposed to explain such complex structures (Fig. 6). The dynamics of the solid inner core is controlled primarily by its viscosity ${ }^{111}$, which has been estimated with values ranging from $10^{-1}$ to $10^{22} \mathrm{~Pa} \mathrm{~s}$ (REFS ${ }^{112,113}$ ), with some estimates suggesting that it is close to liquid viscosity $\left(10^{-1}-10^{2} \mathrm{~Pa} \mathrm{~s}\right)^{113}$. The viscosity of the inner core is dependent on its light element composition through diffusion rate, grain growth rate and shear modulus ${ }^{114}$. The viscosity and thermal conductivity determine the presence or absence of inner core convection $^{112}$. Constraining the inner core composition thus advances our understanding of inner core dynamics and deformation that account for the observed seismic anisotropy ${ }^{110}$.

\section{Bulk Earth light element concentration}

The outer core composition practically represents that of the bulk core, because the inner core contributes only $5 \%$ in mass. The core is a large reservoir, in particular for siderophile elements including $\mathrm{S}\left(\mathrm{REF}^{21}\right), \mathrm{C}\left(\mathrm{REF}^{24}\right)$ and $\mathrm{H}\left(\mathrm{REFS}^{25-27}\right)$. If the core contains the maximum possible amounts of S, C and $\mathrm{H}$ proposed above $(1.7 \mathrm{wt} \% \mathrm{~S}, 0.2 \mathrm{wt} \% \mathrm{C}$ and $0.26 \mathrm{wt} \% \mathrm{H}$ ), the core would host $97 \%, 89 \%$ and $94 \%$ of their planetary budgets, respectively, given BSE concentrations of $250 \mathrm{ppm} \mathrm{S}, 120 \mathrm{ppm} \mathrm{C}\left(\mathrm{REF}^{28}{ }^{28}\right.$ ) and $690 \mathrm{ppm} \mathrm{H}_{2} \mathrm{O}\left(\mathrm{REF}{ }^{115}\right)$. These estimates lead to bulk Earth concentrations of 5,700 ppm S, 730 ppm C and $900 \mathrm{ppm} \mathrm{H}$. The $900 \mathrm{ppm} \mathrm{H}$ 
in the bulk Earth is much larger than the previous estimate of $260 \mathrm{ppm} \mathrm{H}\left(\mathrm{REF}^{28}\right.$ ), based on extrapolating the 'volatility trend' to the low 50\% condensation temperature for hydrogen.

Our estimate of a maximum $4.0 \mathrm{wt} \% \mathrm{Si}$ in the core gives a lower bound for the bulk Earth $\mathrm{Mg} / \mathrm{Si}$ molar ratio of 1.15 , if the composition of the BSE is represented by that of the upper mantle with a 'pyrolitic' composition that possesses an $\mathrm{Mg} / \mathrm{Si}$ ratio of 1.25 . $\mathrm{An} \mathrm{Mg} / \mathrm{Si}$ of $>1.15$ for the bulk Earth is higher than the 1.07 of carbonaceous chondrites and the solar ratio. The difference can be partly attributed to variations in the $\mathrm{Mg} / \mathrm{Si}$ ratio in the solar nebula owing to fractionation of $\mathrm{Mg}_{2} \mathrm{SiO}_{4}$ forsterite ${ }^{55}$. Alternatively, it is also possible that the BSE is not pyrolitic in composition but has $(\mathrm{Mg}, \mathrm{Fe}) \mathrm{SiO}_{3}$ bridgmanite-rich, low $\mathrm{Mg} / \mathrm{Si}$ domains. It is known that bridgmanite crystallises as a single phase until $>50 \%$ solidification of a magma ocean under lower mantle conditions ${ }^{116,117}$. Therefore, the present-day lower mantle could still contain bridgmanite-enriched ancient mantle structures (BEAMS) because such domains would be viscous enough to prevent mixing with a pyrolitic mantle material ${ }^{118}$.

\section{Earth accretion and core formation}

Constraints on the concentrations of individual light elements in the core would provide information on the nature of Earth's building blocks and the path of accretion ${ }^{21,92}$. Accretionary models based on core-mantle element partitioning behaviour predominantly favour a protoEarth initially constructed from reduced material that condensed, volatile free, in the inner solar system. More oxidised material originating in the outer solar system is believed to have been added towards the end of accretion. Core amounts of $\mathrm{Si}, \mathrm{O}$ and $\mathrm{H}$ would provide important input into such scenario, although they are still underconstrained. The core-mantle (metalsilicate) element partitioning behaviour depends on metal composition, in particular S, Si and $\mathrm{O}_{\text {concentrations }}{ }^{22}$. Therefore, knowledge of the core light element concentrations would lead to a better understanding of Earth's core-mantle element partitioning and the conditions of core formation $^{22,89,92,119}$.

$\mathrm{C}$ and $\mathrm{H}$ are highly volatile, and unless they were preserved in presolar grains they should have been transported to our planet from the outer regions of the solar system $(>2.2$ and $>2.7$ AU), where they were condensed from gas to organic matter and ice, respectively. The likely presence of $\mathrm{H}$ in the core suggests $\mathrm{H}_{2} \mathrm{O}$ was delivered not only in the last stage of accretion ${ }^{92}$ and incorporated into core-forming metals via a hydrous magma ocean ${ }^{27}$. The upper bound of $900 \mathrm{ppm} \mathrm{H}$ in the bulk Earth corresponds to 8,100 ppm $\mathrm{H}_{2} \mathrm{O}$, suggesting that up to $\sim 35$ times the current ocean mass of water was possibly brought to our planet ${ }^{27}$. This high water content is consistent with upper estimates for the number of oceans in the Earth from ab initio calculations for hydrogen partitioning between silicate melt and liquid iron at core-forming conditions $^{25}$. These models suggest $\sim 0.26 \mathrm{wt} \% \mathrm{H}$ in the core that corresponds to $\sim 28$ oceans in the core and 7 in the mantle. The transport of such large amount of water to the growing Earth is also consistent with planet formation theories ${ }^{120-122}$, which predict that tens to hundreds of ocean mass of water was accreted to proto-Earth. The estimated bulk Earth inventories of 730 ppm $\mathrm{C}$ and $900 \mathrm{ppm} \mathrm{H}$ yield an $\mathrm{H} / \mathrm{C}$ mass ratio of 1.23, much higher than those of chondrites that are $\sim 0.2$ (REF. ${ }^{123}$ ). It could indicate that Earth's volatiles are not of chondritic origin. Such a carbon deficit could be because of carbon grain destruction in the inner regions of protoplanetary disks before planet formation ${ }^{124}$. It is also possible that a major source of hydrogen was the H-rich protosolar nebular gas ${ }^{125,126}$, a hypothesis supported by the low $\mathrm{D} / \mathrm{H}$ ratio of water in the deep mantle ${ }^{127}$.

\section{Thermal conductivity and geodynamo}

The outer core includes $\mathrm{Ni}$ and light elements, and such impurities substantially reduce the thermal conductivity of Fe. The outer core's thermal conductivity can be doubled depending 
on its light element composition ${ }^{128} \cdot \mathrm{H}^{129}$ and $\mathrm{Si}^{130,131}$ exhibit the least and the largest impurity resistivity, respectively, when they are a single core light element. Within the possible range of the outer core composition proposed above, liquid $\mathrm{Fe}+5 \% \mathrm{Ni}+1.7 \% \mathrm{~S}+4.0 \% \mathrm{Si}+1.4 \%$ $\mathrm{O}+0.2 \% \mathrm{C}$ (by weight) gives a lower bound for the outer core thermal conductivity of $\sim 100$ $\mathrm{W} / \mathrm{m} / \mathrm{K}$ at $\mathrm{CMB}$ conditions ${ }^{128,130}$, although core thermal conductivity still remains controversial $^{132,133}$.

The thermal conductivity of the core has profound implications for its thermal evolution ${ }^{128,134}$. It is known that Earth's strong magnetic field has existed for at least the last $3.5 \mathrm{~Gy}$ and possibly $4.2 \mathrm{~Gy}^{135}$, as a consequence of a dynamo action induced by core convection. A planetary magnetic field has a marked influence on the evolution of surface environments and protects planets from harmful solar wind and cosmic rays. However, the high thermal conductivity of the core ${ }^{128,136}$ suggests that thermally-driven core convection could not be sustained for billions of years ${ }^{134}$. This problem has been called "the new core paradox"137. Indeed, a thermal evolution model ${ }^{134}$ suggested that $T_{\mathrm{CMB}}$ must have exceeded $6,000 \mathrm{~K}$ even in the late Archean era if core convection was driven by thermal buoyancy until the birth of the inner core. Such high $T_{\mathrm{CMB}}$ would have led to whole mantle melting until late Archaean time, which is not consistent with geological records.

Soon after Earth accretion, the core could have included notably more $\mathrm{Si}, \mathrm{Mg}$ and $\mathrm{O}$ than at present (Fig. 5c). In that case, the solubilities of $\mathrm{Si}+\mathrm{O}$ and $\mathrm{Mg}+\mathrm{O}$ in liquid $\mathrm{Fe}$ decrease with decreasing temperature, suggesting that the crystallisation of $\mathrm{SiO}_{2}{ }^{23,84,85}$ and $\mathrm{MgO}^{85,138-140}$ upon secular cooling could be an alternative mechanism to have driven core convection and a dynamo action since the early history of the Earth. However, $\mathrm{MgO}$ crystallisation should occur only when there is $>1.7 \mathrm{wt} \% \mathrm{Mg}$ in the core ${ }^{19,84}$. $>1.7 \mathrm{wt} \% \mathrm{Mg}$ would require that at least part of the core metal equilibrated with silicate in a super-liquidus magma ocean or that the core assimilated some silicate as a result of turbulent mixing ${ }^{20}$ at the time of a giant impact.

\section{Summary and future perspectives}

The chemical compositions of the outer and inner cores are still unknown, but in principle they can be determined by comparing mineral physics data with seismological observations. As discussed above, knowledge of core light element composition is key to a number of unsolved problems on the formation, evolution and present-state of the Earth. It is also helpful to better understand other terrestrial planets in our solar system Mercury, Venus and Mars.

Better estimates of the possible core composition could be obtained with future work using the following additional constraints. First of all, temperature is a fundamental input to estimates of core composition based on comparisons of the densities and velocities of Fe-alloys with the properties of the core at the same temperatures and pressures (Box 1). However, the temperature of the core is not well known. As mentioned above, $T_{\text {ICB }}$ corresponds to the liquidus temperature of an outer core liquid. Knowledge of $T_{\text {ICB }}$ gives the entire core temperature profile, including $T_{\mathrm{CMB}}$ from the observed density profile ${ }^{7,31}$ and the Grüneisen parameter ${ }^{32}$. Nevertheless, the liquidus temperatures of Fe-alloys are also not well known. The melting point of pure $\mathrm{Fe}$ is important as a reference, but its previous estimates at the ICB pressure of $330 \mathrm{GPa}$ ranged from $\sim 5,000 \mathrm{~K}$ to $\sim 7,000 \mathrm{~K}^{103,141-143}$. The effects of light elements on reducing the melting point of Fe can be as much as $\sim 1,000 \mathrm{~K}^{6}$.

To date, the possible ranges of the outer core and inner core compositions have been constrained separately ${ }^{29,30,43,44}$, based on their respective seismological observations (Figs. 3 and 4). Nevertheless, constraining outer and inner core compositions are not separable because the inner core solid crystallised from the outer core liquid. To connect the inner and outer core 
compositions, there needs to be a better understanding of solid-metal to liquid-metal partitioning of the candidate light elements at inner core $P-T$ conditions, considering interactions among the elements (Box 1).

Finally, seismological observations indicate the possibility that the liquid core is stratified at its top ${ }^{144}$ (Fig. 6). This layer, sometimes called the E' layer, exhibits a slow velocity anomaly and is likely to be less dense than the rest of the outer core. However, the lower velocity is not explained by the simple addition of light element(s), because adding more of a given light element causes higher velocity ${ }^{29,30,145}$. The $\mathrm{E}^{\prime}$ layer has been suggested ${ }^{145}$ to be depleted in $\mathrm{Si}$, but enriched in $\mathrm{O}$, as a consequence of chemical reaction with a dense basal magma ocean ${ }^{146}$ that could have been present above the CMB. However, the limited diffusivities ${ }^{147}$ of $\mathrm{Si}$ and $\mathrm{O}$ in liquid Fe could prohibit the formation of the $\sim 300 \mathrm{~km}$ thick $\mathrm{E}^{\prime}$ layer. Understanding the origin of core stratification will also help to constrain the outer core composition.

\section{References}

1. Birch, F. Elasticity and constitution of the Earth's interior. J. Geophys. Res. 57, 227-286 (1952).

2. Birch, F. Density and composition of mantle and core. J. Geophys. Res. 69, 4377-4388 (1964).

3. Nomura, R. et al. Low core-mantle boundary temperature inferred from the solidus of pyrolite. Science 343, 522-525 (2014).

4. Kim, T. et al. Low melting temperature of anhydrous mantle materials at the core-mantle boundary. Geophys. Res. Lett. 47, e2020GL089345 (2020).

5. Lay, T., Hernlund, J. \& Buffett, B. A. Core-mantle boundary heat flow. Nat. Geosci. 1, 25-32 (2008).

6. Fischer, R. A. Melting of Fe alloys and the thermal structure of the core. in Deep Earth: Physics and Chemistry of the Lower Mantle and Core, Geophys. Monogr. 217 (eds. Terasaki, H \& Fischer, R. A.) pp. 3-12 (AGU, Washington, DC, 2016).

7. Dziewonski, A. M. \& Anderson, D. L. Preliminary reference Earth model. Phys. Earth Planet. Inter. 25, 297-356 (1981).

8. Raymond, S. N. \& Morbidelli, A. Planet formation: key mechanisms and global models. Preprint at https://arxiv.org/pdf/2002.05756.pdf (2020).

9. Thibault, Y. \& Walter, M. J. The influence of pressure and temperature on the metalsilicate partition coefficients of nickel and cobalt in a model $\mathrm{C} 1$ chondrite and implications for metal segregation in a deep magma ocean. Geochim. Cosmochim. Acta 59, 991-1002 (1995).

The first study to show that $\mathrm{Ni}$ and $\mathrm{Co}$ become less siderophile with increasing pressure and that segregation of core metal at the base of a deep magma ocean could explain the Ni and Co contents of the bulk silicate Earth (BSE).

10. Li, J. \& Agee, C. B. Geochemistry of mantle-core differentiation at high pressure. Nature 381, 686-689 (1996).

11. Wood, B. J., Walter, M. J. \& Wade, J. Accretion of the Earth and segregation of its core. Nature 441, 825-833 (2006).

12. Poirier, J.-P. Light elements in the Earth's outer core: a critical review. Phys. Earth Planet. Inter. 85, 319-337 (1994).

13. Hirose, K., Labrosse, S. \& Hernlund, J. Composition and state of the core. Annu. Rev. Earth Planet. Sci. 41, 657-691 (2013).

14. Li, J. Composition of the Earth's core. in Encyclopedia of Geology, $2^{\text {nd }}$ edition, pp. 150163 (Elsevier, Amsterdam, 2021). 
15. Speelmanns, I. M., Schmidt, M. W. \& Liebske, C. The almost lithophile character of nitrogen during core formation. Earth Planet. Sci. Lett. 510, 186-197 (2019).

16. Grewal, D. S., Dasgupta, R., Hough, T. \& Farnell, A. Rates of protoplanetary accretion and differentiation set nitrogen budget of rocky planets. Nat. Geosci. 14, 369-376 (2021).

17. Blanchard, I., Siebert, J., Borensztajn, S. \& J. Badro, The solubility of heat-producing elements in Earth's core. Geochem. Persp. Lett. 5, 1-75 (2017).

18. Badro, J., et al. Magnesium partitioning between Earth's mantle and core and its potential to drive an early exsolution geodynamo. Geophys. Res. Lett. 45, 13,240-13,248 (2018).

19. Du, Z., Boujibar, A., Driscoll, P. \& Fei, Y. Experimental constraints on an MgO exsolution-driven dynamo. Geophys. Res. Lett. 44, 7379-7385 (2019).

20. Deguen, R., Olson, P. \& Cardin, P. Experiments on turbulent metal-silicate mixing in a magma ocean. Earth Planet. Sci. Lett. 310, 303-313 (2011).

21. Suer, T. A., Siebert, J., Remusat, L, Menguy, N. \& Fiquet, G. A sulfur-poor terrestrial core inferred from metal-silicate partitioning experiments. Earth Planet. Sci. Lett. 469, 84-97 (2017).

22. Fischer, R. et al. High pressure metal-silicate partitioning of $\mathrm{Ni}, \mathrm{Co}, \mathrm{V}, \mathrm{Cr}, \mathrm{Si}$, and $\mathrm{O}$. Geochim. Cosmochim. Acta 167, 177-194 (2015).

23. Hirose, K. et al. Crystallisation of silicon dioxide and compositional evolution of the Earth's core. Nature 543, 99-102 (2017).

24. Fischer, R., Cottrell, E., Hauri, E., Lee, K. K. M. \& Le Voyer, M. The carbon content of Earth and its core. Proc. Natl. Acad. Sci. USA 117, 8743-8749 (2020).

25. Li, Y., Vočadlo, L., Sun, T. \& Brodholt, J. P. The Earth's core as a reservoir of water. Nat. Geosci. 13, 453-458 (2020).

Ab initio calculations showing how water partitions between silicate and metal, thus showing that the Earth's core may act as a large reservoir for water.

26. Yuan, L. \& Steinle-Neumann, G. Strong sequestration of hydrogen into the Earth's core during planetary differentiation. Geophys. Res. Lett. 47, e2020GL088303 (2020).

27. Tagawa, S. et al. Experimental evidence for hydrogen incorporation into Earth's core. Nat. Commun. 12, 2588 (2021).

Experimentally determined the partitioning of hydrogen between liquid $\mathrm{Fe}$ and molten silicate under high $P$ - $T$ corresponding to conditions of core-forming metal segregation from silicate.

28. McDonough, W. F. Compositional model for the Earth's core. in Treaties in Geochemistry, $2^{\text {nd }}$ edition (eds. Holland, H. D. \& Turekian, K. K) 3, 559-576 (Elsevier, Amsterdam, 2014).

29. Badro, J., Côté, A. S. \& Brodholt, J. P. A seismologically consistent compositional model of Earth's core. Proc. Natl Acad. Sci. USA 111, 7542-7545 (2014).

30. Umemoto, K. \& Hirose, K. Chemical compositions of the outer core examined by first principles calculations. Earth Planet. Sci. Lett. 531, 116009 (2020).

Theoretically calculated the possible range of outer core composition in the Fe-Ni-SSi-O-C-H system that accounts for observed density and velocity.

31. Irving, J. C. E., Cottaar, S. \& Lekic, V. Seismically determined elastic parameters for Earth's outer core. Sci Adv 4, eaar2538.

32. Vočadlo, L., Gillan, M. J. \& Price, G. D. The properties of iron under core conditions from first principles calculations. Phys. Earth Planet. Inter. 140, 101-125 (2003).

$A b$ initio calculations giving a range of properties for solid and liquid iron at core conditions of pressure and temperature.

33. Kuwayama, Y. et al. Equation of state of liquid iron under extreme conditions. Phys. Rev. Lett. 124, 165701 (2020). 
Experimentally determined the quation of state of liquid iron by a combination of XRD and IXS measurements to high $P-T$ close to core conditions.

34. Morard, G. et al. The Earth's core composition from high pressure density measurements of liquid iron alloys. Earth Planet. Sci. Lett. 373, 169-178 (2013).

35. Kawaguchi, S. et al. Sound velocity of liquid Fe-Ni-S at high pressure. J. Geophys. Res. Solid Earth 122, 3624-3634 (2017).

36. Morard, G. et al. Structure and density of Fe-C liquid alloys under high pressure. J. Geophys. Res. Solid Earth 122, 7813-7823 (2017).

37. Nakajima, Y. et al. Silicon-depleted present-day Earth's outer core revealed by sound velocity measurements of liquid Fe-Si alloy. J. Geophys. Res. Solid Earth 125, e2020JB019399 (2020).

38. Nakajima, Y. et al. Carbon-depleted outer core revealed by sound velocity measurements of liquid iron-carbon alloy. Nat. Commun. 6, 8942 (2015).

39. Dewaele, A. et al. Quasihydrostatic equation of state of iron above 2 Mbar. Phys. Rev. Lett. 97, 215504 (2006).

40. Fei, Y., Murphy, C., Shibazaki, Y., Shahar, A. \& Huang, H. Thermal equation of state of hep-iron: constraint on the density deficit of Earth's solid inner core. Geophys. Res. Lett. 43, 6837-6843 (2016).

41. Mao, Z. et al. Sound velocities of Fe and Fe-Si alloy in the Earth's core. Proc. Natl. Acad. Sci. USA 109, 10,239-10,244 (2012).

42. Antonangeli, D. et al. Sound velocities and density measurements of solid hcp-Fe and hcp$\mathrm{Fe}-\mathrm{Si}(9 \mathrm{wt} . \%)$ alloy at high pressure: constraints on the Si abundance in the Earth's inner core. Earth Planet. Sci. Lett. 482, 446-453 (2018).

43. Li, Y., Vočadlo, L. \& Brodholt, J. P. The elastic properties of hcp-Fe alloys under the conditions of the Earth's inner core. Earth Planet. Sci. Lett. 493, 118-127 (2018).

$A b$ initio determination of inner core compositions that match seismological observations.

44. Wang, W., Li, Y., Brodholt, J. P., Vočadlo, L., Walter, M. J. \& Wu, Z. Strong shear softening induced by superionic hydrogen in Earth's inner core. Earth Planet. Sci. Lett. accepted (2021).

45. Tateno, S. et al. Melting experiments on Fe-Si-S alloys to core pressures: silicon in the core? Am. Mineral. 103, 742-748 (2018).

46. Yokoo, S., Hirose, K., Sinmyo, R. \& Tagawa, S. Melting experiments on liquidus phase relations in the Fe-S-O ternary system under core pressures. Geophys. Res. Lett. 46, $5137-$ 5145 (2019).

Determined the liquidus phase relations in the Fe-S-O ternary system, showing the possible compositional range of the outer core liquid that crystallises $\mathrm{Fe}$ at the inner core.

47. Hasegawa, M., Hirose, K., Oka, K. \& Ohishi, Y. Liquidus phase relations and solid-liquid partitioning in the Fe-Si-C system under core pressures. Geophys. Res. Lett. (in press).

48. Tao, R. \& Fei, Y. High-pressure experimental constraints of partitioning behavior of Si and S at the Mercury's inner core boundary. Earth Planet. Sci. Lett. 562, 116849 (2021).

49. Wood, B. J., Smythe, D. J. \& Harrison, T. The condensation temperatures of the elements: a reappraisal. Am. Mineral. 104, 844-856 (2019).

A recent review and revision of element condensation temperatures and volatilities in the solar nebula and their relationships to abundances in the BSE.

50. Dreibus, G. \& Palme, H. Cosmochemical constraints on the sulfur content in the Earth's core. Geochim. Cosmochim. Acta 60, 1125-1130 (1996).

51. Allègre, C. J., Poirier J.-P., Humler, E. \& Hofmann, A. W. The chemical composition of the Earth. Earth Planet. Sci. Lett. 134, 515-526 (1995). 
52. Georg, R. B., Halliday, A. N., Schauble, E. A. \& Reynolds, B. C. Silicon in the Earth's core. Nature 447, 1102-1106 (2007).

Showed that the difference in silicon isotopic composition between the BSE and chondrites could be explained by partitioning of $\mathrm{Si}(\sim 5 \mathrm{wt} \%)$ into Earth's core.

53. Shahar, A. et al. Experimentally determined Si isotope fractionation between silicate and Fe metal and implications for Earth's core formation. Earth Planet. Sci. Lett. 288, 228234 (2009).

54. Hin, R. C., Fitoussi, C., Schmidt, M. W. \& Bourdon, B. Experimental determination of the Si isotope fractionation factor between liquid metal and liquid silicate. Earth Planet. Sci. Lett. 387, 55-66 (2014).

55. Dauphas, N., Poitrasson, F., Burkhardt, C., Kobayashi, H. \& Kurosawa, K. Planetary and meteoritic $\mathrm{Mg} / \mathrm{Si}$ and $\delta^{30} \mathrm{Si}$ variations inherited from solar nebula chemistry. Earth Planet. Sci. Lett. 427, 236-248 (2015).

56. Wasson, J. T. \& Kallemeyn, G. W. Compositions of chondrites. Philos. Trans. R. Soc. London 325, 535-544 (1988).

57. Alfè, D., Gillan, M. J. \& Price, G. D. Composition and temperature of the Earth's core constrained by combining ab initio calculations and seismic data. Earth Planet. Sci. Lett. 195, 91-98 (2002).

$A b$ initio calculations showing that oxygen cannot go into the inner core, and sulfur and silicon equipartition between the inner and outer core, which has significant implications for the composition of the core as a whole.

58. Anderson, W. W. \& Ahrens, T. J. An equation of state for liquid iron and implications for the Earth's core, J. Geophys. Res. 99, 4273-4284 (1994).

59. Sata, N. et al. Compression of $\mathrm{FeSi}, \mathrm{Fe}_{3} \mathrm{C}, \mathrm{Fe}_{0.95} \mathrm{O}$, and $\mathrm{FeS}$ under the core pressures and implication for light element in the Earth's core. J. Geophys. Res. 115, B09204 (2010).

60. Terasaki, H. et al. Stability of Fe-Ni hydride after the reaction between Fe-Ni alloy and hydrous phase $(\delta-\mathrm{AlOOH})$ up to $1.2 \mathrm{Mbar}$ : possibility of $\mathrm{H}$ contribution to the core density deficit. Phys. Earth Planet. Inter. 194-195, 18-24 (2012).

61. Jing, Z. et al. Sound velocity of Fe-S liquids at high pressure: implications for the Moon's molten outer core. Earth Planet. Sci. Lett. 396, 78-87 (2014).

62. Nishida, K. et al. Effect of sulfur on sound velocity of liquid iron under Martian core conditions. Nat. Commun. 11, 1954 (2020).

63. Ozawa, H., Hirose, K., Tateno, S., Sata, N. \& Ohishi, Y. Phase transition boundary between B1 and B8 structures of FeO up to $210 \mathrm{GPa}$. Phys. Earth Planet. Inter. 179, 157163 (2010).

64. Chen, B. et al. Hidden carbon in Earth's inner core revealed by shear softening in dense $\mathrm{Fe}_{7} \mathrm{C}_{3}$. Proc. Natl. Acad. Sci. USA 111, 17755-17758 (2014).

65. Prescher, C. et al. High Poisson's ratio of Earth's inner core explained by carbon alloying. Nat. Geosci. 8, 220-223 (2015).

66. Sakamaki, T. et al. Constraints on Earth's inner core composition inferred from measurements of the sound velocity of hcp-iron in extreme conditions. Sci. Adv. 2, e1500802 (2016).

67. Masters, G. \& Gubbins, D. On the resolution of density within the Earth. Phys. Earth Planet. Inter. 140, 159-167 (2003).

68. Vočadlo, L. al. The stability of bcc-Fe at high pressures and temperatures with respect to tetragonal strain. Phys. Earth Planet. Int. 170, 52-59 (2008).

69. Tateno, S., Hirose, K., Ohishi, Y. \& Tatsumi, Y. The structure of iron in Earth's inner core. Science 330, 359-361 (2010). 
70. Jackson, I., Fitz Gerald, J. D. \& Kokkonen, H. High temperature viscoelastic relaxation in iron and its implications for the shear modulus and attenuation of the Earth's inner core. $J$. Geophys. Res. Solid Earth 105, 23605-23634 (2000).

71. Li, Y., Vočadlo, L., Brodholt, J. \& Wood, I. G. Thermoelasticity of $\mathrm{Fe}_{7} \mathrm{C}_{3}$ under inner core conditions. J. Geophys. Res. Solid Earth 121, 5828-5837 (2016).

72. Tateno, S. et al. $\mathrm{Fe}_{2} \mathrm{~S}$ : the most Fe-rich iron sulfide at the Earth's inner core pressures. Geophys. Res. Lett. 46, 11944-11949 (2019).

73. Mashino, I. et al. Melting experiments on the Fe-C binary system up to $255 \mathrm{GPa}$ : constraints on the carbon content in the Earth's core. Earth Planet. Sci. Lett. 515, 135-144 (2019).

74. Fukai, Y. Some properties of the Fe-H system at high pressures and temperatures, and their implications for the Earth's core. in High-Pressure Research: Application to Earth and Planetary Sciences, Geophys. Monogr. 67 (eds. Syono, Y. \& Manghnani, M. H.) pp. 373385 (TERRAPUB, Tokyo, 1992).

75. Mori, Y. et al. Melting experiments on $\mathrm{Fe}-\mathrm{Fe}_{3} \mathrm{~S}$ system to $254 \mathrm{GPa}$. Earth Planet. Sci. Lett. 464, 135-141 (2017).

76. Oka, K. et al. Melting in Fe-FeO to $204 \mathrm{GPa}$ : implications for oxygen in Earth's core. Am. Mineral. 104, 1603-1607 (2019).

77. Stewart, A. J., Schmidt, M. W., van Westrenen, W. \& Liebske, C. Mars: a new core crystallization regime. Science 316, 1323-1325 (2007).

78. Gilfoy, F. \& Li, J. Thermal state and solidification regime of the martian core: insights from the melting behavior of FeNi-S at $20 \mathrm{GPa}$. Earth Planet. Sci. Lett. 541, 116285 (2020).

79. Imai, T. Crystal/melt partitioning under deep mantle conditions and melting phase relation in the system Fe-FeH. Doctoral Thesis, Tokyo Institute of Technology (2013).

80. Pépin, C. M., Dewaele, A., Geneste, G. \& Loubeyre, P. New iron hydrides under high pressure. Phys. Rev. Lett. 113, 265504 (2014).

81. O'Neill, H. St. C., Canil, D. \& Rubie, D. C. Oxide-metal equilibria at $2500^{\circ} \mathrm{C}$ and $25 \mathrm{GPa}$ : implications for core formation and the light component in the Earth's core. J. Geophys. Res. Solid Earth 103, 12239-12260 (1998).

82. Takahashi, $\mathrm{S}$. et al. Phase relations in the carbon-saturated $\mathrm{C}-\mathrm{Mg}-\mathrm{Fe}-\mathrm{Si}-\mathrm{O}$ system and $\mathrm{C}$ and $\mathrm{Si}$ solubility in liquid $\mathrm{Fe}$ at high pressure and temperature: implications for planetary interiors. Phys. Chem. Miner. 40, 647-657 (2013).

83. Hirose, K. et al. Hydrogen limits carbon in liquid iron. Geophys. Res. Lett. 46, 5190-5197 (2019).

84. Helffrich, G., Hirose, K. \& Nomura, R. Thermodynamical modeling of liquid Fe-Si-MgO: molten magnesium silicate release from the core. Geophys. Res. Lett. 47, e2020GL089218 (2020).

85. Mittal, T. et al. Precipitation of multiple light elements to power Earth's early dynamo. Earth Planet. Sci. Lett. 532, 116030 (2020).

86. Arveson, S. M., Deng, J., Karki, B. B. \& Lee, K. K. M. Evidence for Fe-Si-O liquid immiscibility at deep Earth pressures. Proc. Natl Acad. Sci. USA 116, 10,238-10,243 (2019).

87. Ringwood, A. E. The chemical composition and origin of the Earth. in Advances in Earth Sciences (ed. Hurley, P. M.) 287-356 (MIT Press, Cambridge, 1966).

88. Palme, H. \& O'Neill, H. St. C. Cosmochemical estimates of mantle composition. in Treatise on Geochemistry, $2^{\text {nd }}$ edition (eds. Holland, H. D. \& Turekian, K. K) 3, 1-39 (Elsevier, Amsterdam, 2014).

89. Wade, J. \& Wood, B. J. Core formation and the oxidation state of the Earth. Earth Planet. Sci. Lett. 236, 78-95 (2005). 
Used experimental metal-silicate partitioning data to show that a continuous accretion model in which the Earth grew from a small reduced body to a large more oxidised body could explain the current composition of the BSE.

90. Wade, J., Wood, B. J. \& Tuff, J. Metal-silicate partitioning of Mo and W at high pressures and temperatures: evidence for late accretion of sulphur to the Earth. Geochim. Cosmochim. Acta 85, 58-74 (2012).

91. Wood, B. J. Accretion and core formation: constraints from metal-silicate partitioning, Phil. Trans. R. Soc. A 366, 4339-4355 (2008).

92. Rubie, D. C. et al. Accretion and differentiation of the terrestrial planets with implications for the compositions of early-formed solar system bodies and accretion of water. Icarus 248, 89-108 (2015).

93. Tuff, J., Wood, B. J. \& Wade, J. The effect of Si on metal-silicate partitioning of siderophile elements and implications for the conditions of core formation. Geochim. Cosmochim. Acta 75, 673-690 (2011).

94. Siebert, J., Badro, J., Antonangeli, D. \& Ryerson, F. J. Terrestrial accretion under oxidising conditions. Science 339, 1194-1197 (2013).

95. Wood, B. J. Carbon in the core. Earth Planet. Sci. Lett. 117, 593-607 (1993).

96. Iizuka-Oku, R. et al. Hydrogenation of iron in the early stage of Earth's evolution. Nat. Commun. 8, 14096 (2017).

97. Clesi, V. et al. Low hydrogen contents in the cores of terrestrial planets. Sci. Adv. 4, e1701876 (2018).

98. Malavergne, V. et al. Experimental constraints on the fate of $\mathrm{H}$ and $\mathrm{C}$ during planetary core-mantle differentiation. Implications for the Earth. Icarus 321, 473-485 (2019).

99. Satish-Kumar, M., So, H., Yoshino, T., Kato, M. \& Hiroi, Y. Experimental determination of carbon isotope fractionation between iron carbide melt and carbon: ${ }^{12} \mathrm{C}$-enriched carbon in the Earth's core? Earth Planet. Sci. Lett. 310, 340-348 (2011).

100.Labidi, J. et al. Experimentally determined sulfur isotope fractionation between metal and silicate and implications for planetary differentiation. Geochim. Cosmochim. Acta 175, 181-194 (2016).

101.Allègre, C., Manhès, G. \& Lewin, È. Chemical composition of the Earth and the volatility control on planetary genetics. Earth Planet. Sci. Lett. 185, 49-69 (2001).

102.Morard, G. et al. $\mathrm{Fe}-\mathrm{FeO}$ and $\mathrm{Fe}-\mathrm{Fe}_{3} \mathrm{C}$ melting relations at Earth's core-mantle boundary conditions: implications for a volatile-rich or oxygen-rich core. Earth Planet. Sci. Lett. 473, 94-103 (2017).

103.Alfè, D. Temperature of the inner-core boundary of the Earth: melting of iron at high pressure from first-principles coexistence simulations. Phys. Rev. B 79, 060101(R) (2009).

104.Hernlund, J. W. \& McNamara, A. K. The core-mantle boundary region. in Treatise on Geophysics, $2^{\text {nd }}$ edition (ed. Schubert, G.) 7, 461-519 (Elsevier, Amsterdam, 2015).

105.Hirose, K., Wentzcovitch, R., Yuen, D. \& Lay, T. Mineralogy of the deep mantle - the post-perovskite phase and its geophysical significance. in Treatise on Geophysics, $2^{\text {nd }}$ edition (ed. Schubert, G.) 2, 85-115 (Elsevier, Amsterdam, 2015).

106.Koppers, A. A. P. et al. Mantle plumes and their role in Earth processes. Nat. Rev. Earth Environ. 2, 382-401 (2021).

107.Williams, Q. \& Garnero, E. J. Seismic evidence for partial melt at the base of Earth's mantle. Science 273, 1528-1530 (1996).

108.Wicks, J. K., Jackson, J. M. \& Sturhahn, W. Very low sound velocities in iron-rich $(\mathrm{Mg}, \mathrm{Fe}) \mathrm{O}$ : implications for the core-mantle boundary region. Geophys. Res. Lett. 37, L15304 (2010). 
109.Cobden, L., Mosca, I., Trampert, J. \& Ritsema, J. On the likelihood of post-perovskite near the core-mantle boundary: a statistical interpretation of seismic observations. Phys. Earth Planet. Inter. 210-211, 21-35 (2012).

110.Souriau, A. \& Calvet, M. Deep earth structure: the Earth's cores. in Treatise on Geophysics, $2^{\text {nd }}$ edition (ed. Schubert, G.) 1, 725-757 (Elsevier, Amsterdam, 2015).

111.Vočadlo, L. Core viscosity. in Encyclopedia of geomagnetism and paleomagnetism (eds. Gubbins, D. \& Herrero-Bervera, E.) pp. 104 (Kluwer, Amsterdam, 2007).

112.Lasbleis, M \& Deguen, R. Building a regime diagram for the Earth's inner core. Phys. Earth Planet. Inter. 247, 80-93 (2015).

113.Belonoshko, A. B., Fu, J., Bryk, T., Simak, S. I. \& Mattesini, M. Low viscosity of the Earth's inner core. Nat. Commun. 10, 2483 (2019).

114.Reaman, D. M., Daehn, G. S. \& Panero, W. R. Predictive mechanism for anisotropy development in the Earth's inner core. Earth Planet. Sci. Lett. 312, 437-442 (2011).

115.Hirschmann, M. M. Constraints on the early delivery and fractionation of Earth's major volatiles from C/H, C/N, and C/S ratios. Am. Mineral. 101, 540-553 (2016).

116. Tateno, S., Hirose, K. \& Ohishi, Y. Melting experiments on peridotite to lowermost mantle conditions. J. Geophys. Res. Solid Earth 119, 4684-4694 (2014).

117.Caracas R., Hirose, K., Nomura \& Ballmer, M. D. Melt-crystal density crossover in a deep magma ocean. Earth Planet. Sci. Lett. 516, 202-211 (2019).

118.Ballmer, M., Houser, C., Hernlund, J., Wentzcovitch, R. \& Hirose, K. Persistence of strong silica-enriched domains in the Earth's lower mantle, Nat. Geosci. 10, 236-240 (2017).

119.Badro, J., Brodholt, J. P., Piet, H., Siebert, J. \& Ryerson, F. J. Core formation and core composition from coupled geochemical and geophysical constraints. Proc. Natl Acad. Sci. USA 112, 12310-12314 (2015).

120.Walsh, K. J., Morbidelli, A., Raymond, S. N., O'Brien, D. P. \& Mandell, A. M. A low mass for Mars from Jupiter's early gas-driven migration. Nature 475, 206-209 (2011).

121.Sato, T., Okuzumi, S. \& Ida, S. On the water delivery to terrestrial embryos by ice pebble accretion. Astron. Astrophys. 589, A15 (2016).

122.Raymond, S. N., Quinn, T. \& Lunine, J. I. High-resolution simulations of the final assembly of Earth-like planets. 2. Water delivery and planetary habitability. Astrobiology 7, 66-84 (2007).

123.Hirschmann, M. M. \& Dasgupta, R. The H/C ratios of Earth's near-surface and deep reservoirs, and consequences for deep Earth volatile cycles. Chem. Geol. 262, 4-16 (2009).

124.Wei, C.-E. et al. The effect of carbon grain destruction on the chemical structure of protoplanetary disks. Astrophys. J. 870, 129 (2019).

125.Ikoma, M. \& Genda, H. Constraints on the mass of a habitable planet with water of nebular origin. Astrophys. J. 648, 696Y706 (2006).

126. Olson, P. \& Sharp, Z. D. Nebular atmosphere to magma ocean: a model for volatile capture during Earth accretion. Phys. Earth Planet. Inter. 294, 106294 (2019).

127.Hallis, L. J. et al. Evidence for primordial water in Earth's deep mantle. Science 350, 336339 (2015).

128.Gomi, H. et al. The high conductivity of iron and thermal evolution of the Earth's core. Phys. Earth Planet. Inter. 224, 88-103 (2013).

129.Ohta, K., Suehiro, S., Hirose, K. \& Ohishi, Y. Electrical resistivity of fcc phase iron hydrides at high pressures and temperatures. Comptes Rendus Geosci. 351, 147-153 (2019).

130.Gomi, H., Hirose, K., Akai, H. \& Fei, Y. Electrical resistivity of substitutionally disordered hcp Fe-Si and Fe-Ni alloys: chemically induced resistivity saturation in the Earth's core. Earth Planet. Sci. Lett. 451, 51-61 (2016). 
131.Inoue, H., Suehiro S., Ohta, K., Hirose, K. \& Ohishi, Y. Resistivity saturation of hcp Fe$\mathrm{Si}$ alloys in an internally-heated diamond anvil cell: a key to assess the Earth's core conductivity. Earth Planet. Sci. Lett. 543, 116357 (2020).

132.Zhang, Y. et al. Reconciliation of experiments and theory on transport properties of iron and the geodynamo. Phys. Rev. Lett. 125, 078501 (2020).

133.Ohta, K. \& Hirose, K. The thermal conductivity of the Earth's core and implications for its thermal and compositional evolution. Nat. Sci. Rev. 8, nwaa303 (2021).

134.Labrosse, S. Thermal evolution of the core with a high thermal conductivity. Phys. Earth Planet. Inter. 247, 36-55 (2015).

135. Tarduno, J. A. et al. Paleomagnetism indicates that primary magnetite in zircon records a strong Hadean geodynamo. Proc. Natl. Acad. Sci. USA 117, 2309-2318 (2020).

136.Pozzo, M., Davies, C., Gubbins, D. \& Alfè, D. Thermal and electrical conductivity of iron at Earth's core conditions. Nature 485, 355-358 (2012).

137. Olson, P. The new core paradox. Science 342, 431-432 (2015).

138. O'Rourke, J. G. \& Stevenson, D. J. Powering Earth's dynamo with magnesium precipitation from the core. Nature 529, 387-389 (2016).

139.Badro, J. Siebert, J. \& Nimmo, F. An early geodynamo driven by exsolution of mantle components from Earth's core. Nature 536, 326-328 (2016).

140.Du, Z. et al. Insufficient energy from $\mathrm{MgO}$ exsolution to power early geodynamo. Geophys. Res. Lett. 44, 11,376-11,381 (2017).

141.Boehler, R. Temperatures in the Earth's core from melting-point measurements of iron at high static pressures. Nature 363, 534-536 (1993).

142.Anzellini, S., Dewaele, A., Mezouar, M., Loubeyre, P. \& Morard, G. Melting of iron at Earth's inner core boundary based on fast X-ray diffraction. Science 340, 464-466 (2013).

143.Sinmyo, R., Hirose, K. \& Ohishi, Y. Melting curve of iron to $290 \mathrm{GPa}$ determined in a resistance-heated diamond-anvil cell. Earth Planet. Sci. Lett. 510, 45-52 (2019).

144.Helffrich, G. \& Kaneshima, S. Outer-core compositional stratification from observed core wave speed profiles. Nature 468, 807-812 (2010).

145.Brodholt, J. \& Badro, J. Composition of the low seismic velocity E' layer at the top of Earth's core. Geophys. Res. Lett. 44, 8303-8310 (2017).

146.Labrosse, S., Hernlund, J. W. \& Coltice, N. A crystallising dense magma ocean at the base of the Earth's mantle. Nature 450, 866-869 (2007).

147.Helffrich, G. Outer core compositional layering and constraints on core liquid transport properties. Earth Planet. Sci. Lett. 391, 256-262 (2014).

148.Biggin, A. et al. Palaeomagnetic field intensity variations suggest Mesoproterozoic innercore nucleation. Nature 526, 245-248 (2015).

149.Ohta, K., Kuwayama, Y., Hirose, K., Shimizu, K. \& Ohishi, Y. Experimental determination of the electrical resistivity of iron at Earth's core conditions. Nature 534, 95-98 (2016).

150.Ozawa, H., Hirose, K., Yonemitsu, K. \& Ohishi, Y. High-pressure melting experiments on $\mathrm{Fe}-\mathrm{Si}$ alloys and implications for silicon as a light element in the core. Earth Planet. Sci. Lett. 456, 47-54 (2016).

151.Li, Y., Vočadlo, L., Alfè, D. \& Brodholt, J. P. Carbon partitioning between the Earth's inner and outer core. J. Geophys. Res. Solid Earth 124, 12812-12824 (2019).

\section{Acknowledgements}

We thank K. Umemoto for his help in preparing the manuscript. 


\section{Author contributions}

The authors contributed equally to all aspects of the article.

\section{Competing interests}

The authors declare no competing interests

\section{Peer review information}

Nature Reviews Earth \& Environment thanks [Referee\#1 name], [Referee\#2 name] and the other, anonymous, reviewer(s) for their contribution to the peer review of this work.

\section{Publisher's note}

Springer Nature remains neutral with regard to jurisdictional claims in published maps and institutional affiliations.

\section{Supplementary information}

Supplementary information is available for this paper at https://doi.org/10.1038/s415XXXXX-XXXX-X 


\section{Figure captions}

Fig. 1 | Formation of Earth's core and present-day internal structure. a| During early Earth accretion $(>4.5 \mathrm{Ga}$ ), the core formed by segregation of molten metals derived from impactors, which sank through a magma ocean owing to their higher density. The metal phases chemically equilibrated with silicate melts at the bottom of the magma ocean. The inner core could have crystallised much more recently, around 1.3-0.7 $\mathrm{Ga}^{148,149}$. b| The present-day internal structure of the Earth. The liquid and solid core compositions are constrained by seismological observations ${ }^{7,31}$. The density and velocity of the outer and inner core can help inform estimates of the Fe-Ni-S-Si$\mathrm{O}-\mathrm{C}-\mathrm{H}$ composition. Crystallisation of the dense inner core $47,73,75,76$, metal-silicate partitioning during core formation ${ }^{21-27}$, exsolution of oxides ${ }^{23,84,85,138-140}$ and formation of a low-velocity layer (the $E^{\prime}$ layer) atop the core ${ }^{145}$ could be additional important constraints on core composition.

Fig. 2 | Concentrations of elements in Bulk Silicate Earth relative to primitive meteorites. The difference between the Bulk Silicate Earth (BSE) concentration and the volatility trend gives an estimate of the abundance for each element in the core, except for highly volatile elements. The BSE concentrations are normalised to those of $\mathrm{Cl}$ chondrites and $\mathrm{Ca}=1.0$ and plotted versus the temperature at which $50 \%$ of the element would be condensed from a gas of solar composition at $10 \mathrm{~Pa}^{49}$. The black line represents the 'volatility trend' of decreasing abundance of lithophile elements with decreasing condensation temperature, showing the depletion from chondritic abundance owing to volatility.

Fig. 3 | The effects of light elements and $\mathrm{Ni}$ on outer core density and velocity. $\mathrm{Ni}$ (black) and each light element, Si (red), C (purple), S (blue), O (yellow) and $\mathrm{H}$ (green), exhibit different effects on the density and velocity of liquid $\mathrm{Fe}$, which is used to constrain the outer core composition by comparing with observations. a| Liquid density at core-mantle boundaty $(\mathrm{CMB})$ conditions, $\mathbf{b}$ | liquid density at inner core boundary (ICB) conditions, c| P-wave velocity at CMB conditions and $\mathbf{d} \mid \mathrm{P}$-wave velocity at ICB conditions. Seismologocal observations (Preliminary Reference Earth Model, PREM) ${ }^{7}$ are given with uncertainty bands ${ }^{30}$ that are estimated by considering resolution ${ }^{67}$. Solid and broken curves were calculated by assuming $T_{\mathrm{ICB}}=5,400 \mathrm{~K}^{30}$ and $T_{\mathrm{ICB}}=6,300 \mathrm{~K}^{29}$, respectively. All panels adapted with permission from REF. ${ }^{30}$, Elsevier.

Fig. 4 | Possible range of the inner core composition in the Fe-S-Si-C system. The compositions of Fe alloyed with small amounts of S, Si and C best match the seismologically determined observations (Preliminary Reference Earth Model, PREM) ${ }^{7}$ for a| shear velocity $\left(V_{S}\right), \mathbf{b} \mid$ compressional velocity $\left(V_{P}\right)$, and $\mathbf{c} \mid$ density $(\rho)$ within tolerance (red-blue colour bars are the \% difference $(\sigma)$ between the calculations and PREM), as demonstrated by ab initio calculations at inner core conditions. There are two sets of acceptable matching compositions for each property, representing results from calculations at $6,000 \mathrm{~K}$ and $6,500 \mathrm{~K}$. The boxes are guides for the eye that represent possible ranges on the concentration axes in atomic fraction. A wide range of Fe-S-Si-C compositions ${ }^{43}$ can thus be matched to the seismological data ${ }^{7}$. Panels $\mathbf{a}, \mathbf{b}$ and $\mathbf{c}$ are adapted from REF ${ }^{43}$, CC BY 4.0. 
Fig. 5 | Constraints on liquid core composition. a | Fe-S-O ternary liquidus (melting) phase relations ${ }^{46}$. The red colored region is the liquidus field of $\mathrm{Fe}$ at Inner Core Boundary (ICB) pressure, indicating the compositional range of liquids that crystallise $\mathrm{Fe}$ at the inner core, but neither $\mathrm{FeO}$ nor $\mathrm{Fe}_{2} \mathrm{~S}$. b, c $\mid$ Simultaneous solubility limits of $\mathrm{Si}+\mathrm{O}$ in liquid $\mathrm{Fe}$ at $0.1 \mathrm{MPa}^{81}$ and $136 \mathrm{GPa}\left(=P_{\mathrm{CMB}}\right)^{84}$. The $\mathrm{Si}$ and $\mathrm{O}$ contents in the initial core proposed by refs. "S" 94, "R" 92 and "F" 22 exceed the solubility limit in the present-day uppermost outer core, which has led to the crystallisation of $\mathrm{SiO}_{2}$ and depletion in $\mathrm{Si}$ and $\mathrm{O}$ in the liquid core over the Earth's history (arrows). Errors are derived from uncertainties in $P$ and $T$ conditions for core metal segregation from silicate as well as in metal-silicate partitioning of $\mathrm{Si}$ and $\mathrm{O}$. The $\mathrm{Si}$ and $\mathrm{O}$ concentrations in the present-day outer core might lie on the simultaneous solubility curve for $T_{\mathrm{CMB}}=$ $\sim 4,000 \mathrm{~K}$. Panel a adapted with permission from REF.46, Wiley (C) 2019. American Geophysical Union. All Rights Reserved.

Fig. 6 Implications of the core light elements. The core light element composition is a key to understanding the present state (for example, core temperatures ${ }^{3-6}$ ) and dynamics of the core ${ }^{111-114,128,134}$ and the lowermost mantle ${ }^{104-106}$. Core composition provides insight into the mechanism of liquid core convection ${ }^{23,84,85,138-140}$ and the geodynamo, which in turn add insight to the sustainability of Earth's magnetic field. The outer core composition also constrains the origin of the low-velocity layer (the $E^{\prime}$ layer) at its top ${ }^{145}$. The core light element concentrations connect to the overall bulk Earth composition and the conditions of core formation, which provides information on Earth's building blocks and accretion history21,24,27,92

\section{Boxes}

\section{Box 1 | Solid metal to liquid metal partitioning}

The mismatch between seismic observations of core density and experimental or theoretical constraints on pure Fe density requires a 'light' element component in the core (Box Figure). $\sim 5 \% \mathrm{Ni}$ is believed to be included in the core, but as $\mathrm{Ni}$ is heavier than $\mathrm{Fe}$ it, therefore, does not help to explain the lower density of the Earth's core.

The partitioning of elements between liquid and solid metal can provide some of the necessary additional constraints on the inner core composition from that of the outer core, and vice versa. If we take a model liquid outer core composition, element partitioning can be used to calculate the inner core solid composition, which can then be tested against observational data. Partition coefficients $\left(D^{\text {solid/liquid }}\right)$ have been estimated by experiments and $a b$ initio calculations to be $\sim 0.8$ for $\mathrm{S}^{46,57}, \sim 1$ for $\mathrm{Si}^{57,150}, 0$ for $\mathrm{O}^{46,57}, 0-0.33$ for $\mathrm{C}^{73,151}$ and $\sim 0.7$ for $\mathrm{H}^{79}$ in binary Fe-alloy systems. However, some caution is needed in interpreting these results because solid/liquid partitioning determined in the Fe-S and $\mathrm{Fe}$-Si binary systems is likely to be very different from that in the Fe-S-Si ternary system ${ }^{45,48}$ because of the well-known S-Si interactions in metallic liquids.

Nevertheless, S, Si and $\mathrm{H}$ compatibility in the solid inner core means that the outer core must contain at least some $\mathrm{O}$ and/or $\mathrm{C}$. Therefore, to match the density jump across the ICB (Box Figure), the outer core must contain at least one element that is incompatible with the inner core. $\mathrm{O}$ and $\mathrm{C}$ match this requirement.

In the figure, blue lines with $\pm \sim 1 \%$ uncertainty band were determined by experiments (for the outer core $^{33}$, and inner core ${ }^{39}$ ). Black lines, calculated by theory ${ }^{32}$. Seismic observations are 
represented by closed circles (Preliminary Reference Earth Model - PREM) ${ }^{7}$ and open circles (Elastic Parameters of the Outer Core - EPOC) ${ }^{31}$.

\section{Glossary}

- Bulk silicate Earth (BSE) - a combination of mantle and crust that are made of silicate rocks

- Ab initio calculations - purely theoretical calculations without inputs from experimental results

- Static compression experiments - the opposite of 'dynamic compression experiments' in which high-pressure and -temperature conditions are generated in a very short period of time $(\sim 1 \mu \mathrm{sec})$

- Carbonaceous chondrite meteorites - a group of C-rich primitive meteorites

- CI chondrites - primitive meteorites with compositions silimar to that of the solar system for refractory elements

- Refractory - the opposite of 'volatile'

- chondritic reference - reference based on primitive meteorites that are similar in composition to the solar system

- diamond-anvil cell (DAC) - a device gerenating high pressure by using a couple of diamonds (the hardest material known to date) with which high pressures beyond that at the center of the Earth can be generated.

- hcp structure - hexagonal close-packed crystal structure, one of the closest packed structures

- eutectic point - a composition and a temperature at which eutectic melting (melting in a two- or more component system in which all components are not soluble into a single solid phase) occurs

- eutectic liquid - a liquid coexisting with the number of solid phases same as that of components

- simultaneous solubility limits - the maximum amounts of two (or more) elements that dissolve together into a liquid

- $\quad$ bcc Fe - solid iron with the body-centered-cubic crystal structure 


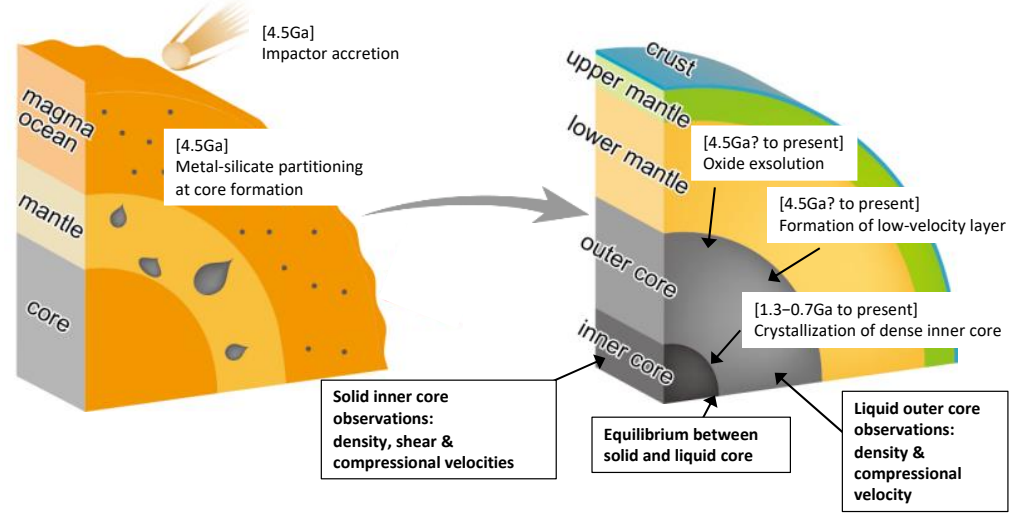

Fig. 1

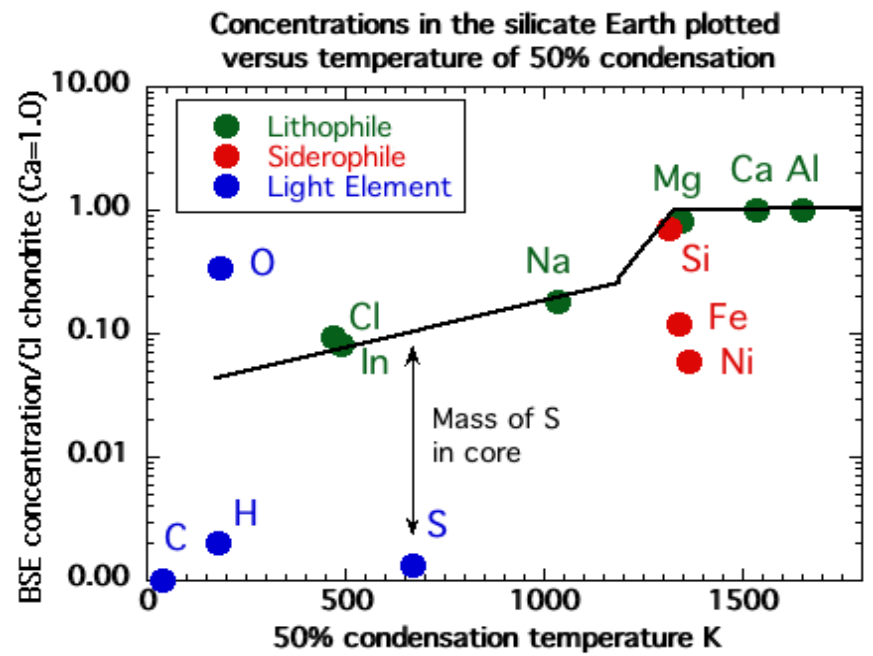

Fig. 2 
a
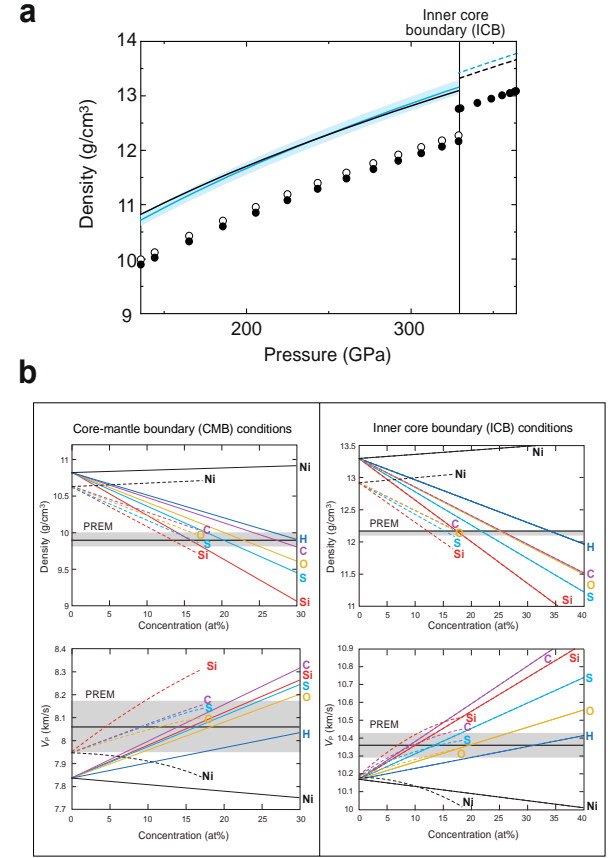

Fig. 3

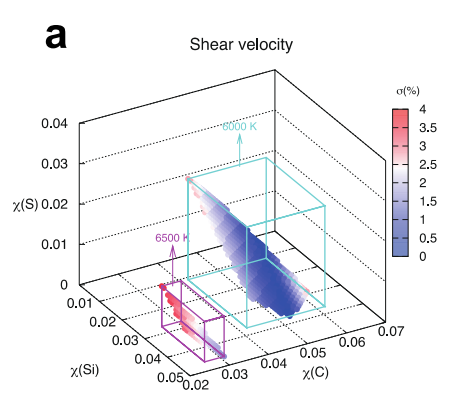

b compressional velocity

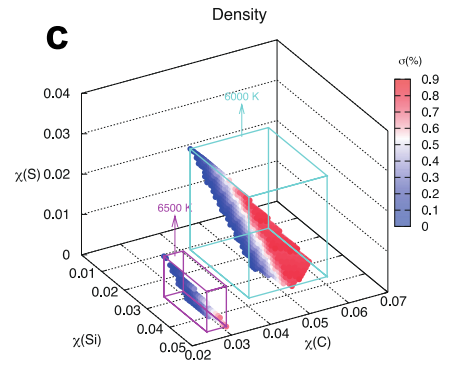

Fig. 4 
a
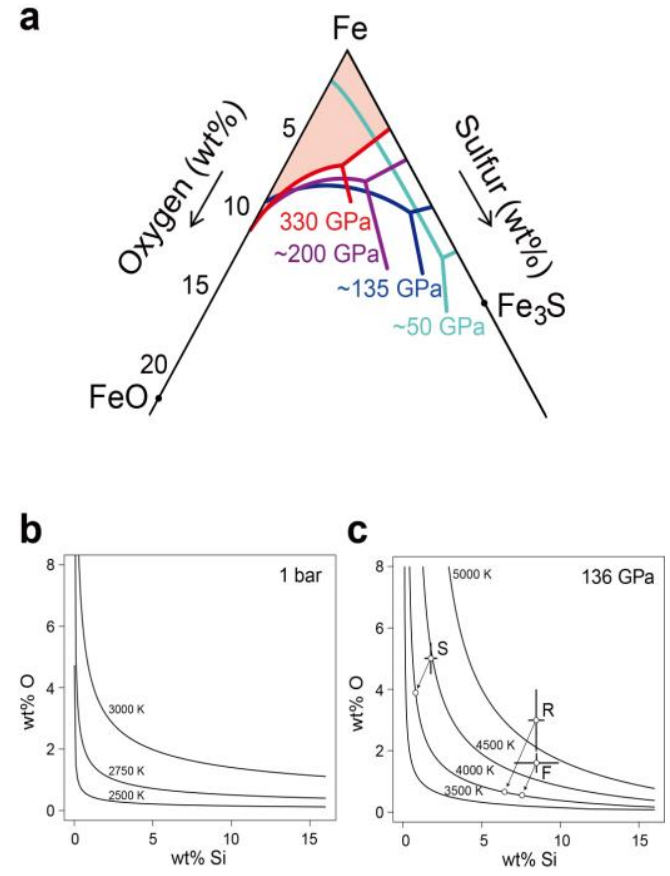

Fig. 5

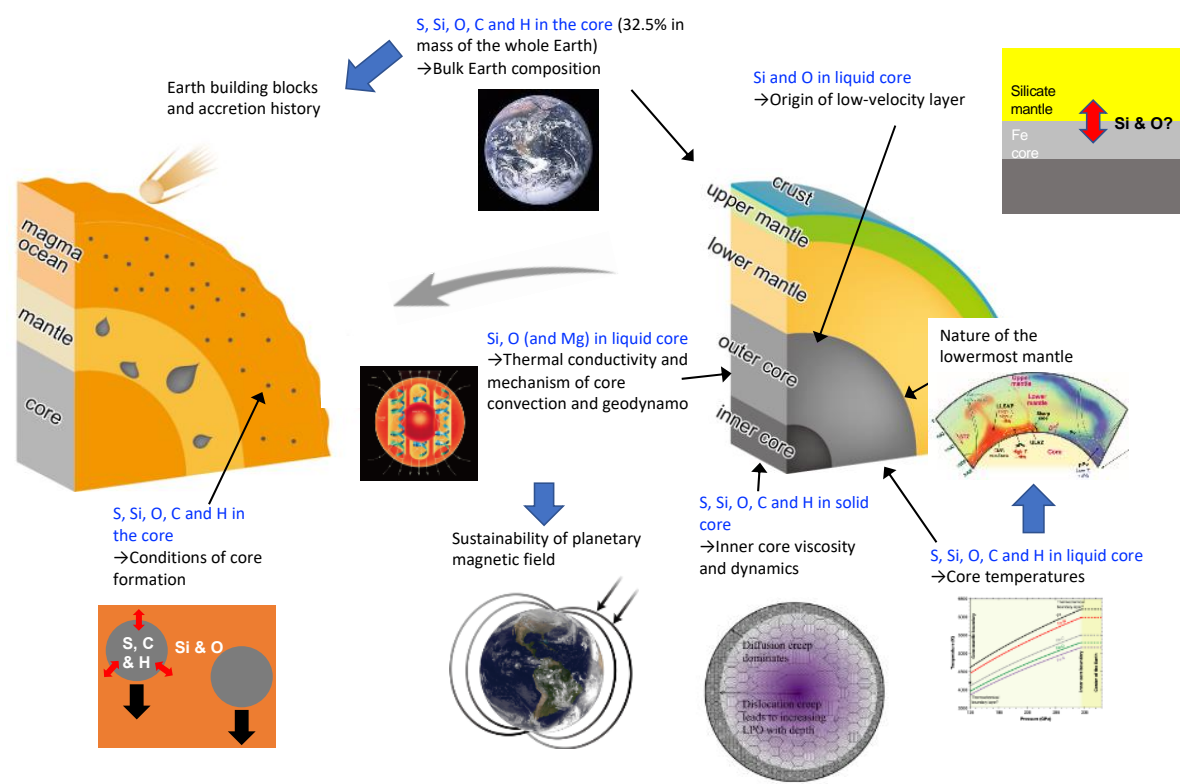

Fig. 6 